\title{
A Critique of Shareholder Value Maximization
}

\author{
Michael MAGILL \\ University of Southern California \\ magill@usc.edu \\ Martine QUINZII \\ University of California, Davis \\ mmquinzii@ucdavis.edu \\ Jean-Charles ROCHET \\ University of Zürich, SFI, and Toulouse School of Economics (IDEI) \\ jean-charles.rochet@bf.uzh.ch
}

December 16, 2013

\begin{abstract}
The majority of economists share the view that a firm - even a large corporation - should serve the exclusive interests of its shareholders. This paper argues that shareholder value maximization is not a socially optimal criterion when large firms make investment decisions which either decrease the probability of adverse technological outcomes or increase the probability of producing more efficiently (firm-specific innovations). Such investments affect the expected prices on the product and labor markets on which the firms operate, thereby influencing not only the firms' expected profits but also the expected welfare of consumers and workers (a pecuniary externality). This suggests that a firm's criterion should include the welfare of its stakeholders. We show that when firms are stakeholder oriented in that they maximize a weighted sum of shareholder value and their contribution to consumer and employee welfare, then the resulting stakeholder equilibrium improves upon the shareholder equilibrium.
\end{abstract}

Keywords: Shareholder Value Maximization, Stakeholder Model, Endogenous Uncertainty.

JEL : D50,G39

Acknowledgments: We are grateful to the Editor, Daron Acemoglu, and four anonymous referees for excellent comments and suggestions. We also thank participants in many seminar and conferences, notably Manuel Arellano, Doug Bernheim, the late Sudipto Bhattacharya, Bruno Biais, Luis Braido, Patrick Bolton, Hans Degryse, Jacques Drèze, Jean Fraysse, Hans Gersbach, Piero Gottardi, Roger Guesnerie, Michel Habib, Jim Hammitt, Henry Hansmann, Jim Heckman, Gerard Hertig, Philippe Jéhiel, Bruno Jullien, George Mailath, Thomas Mariotti, David Martimort, Filipe Martins-da-Rocha, Marco Pagano, Tom Palfrey, Phil Reny, Rafael Repullo, Patrick Rey, Klaus Ritzberger, Howard Rosenthal, Suzanne Scotchmer, Paul Seabright, Lars Stole and Jean Tirole for helpful discussions and encouragement. Rochet acknowledges financial support from the European Research Council (European Community's Seventh Framework Programme, grant agreement 249415-RMAC) and from NCCR FinRisk (project Banking and Regulation). 


\section{Introduction}

That all firms, even large corporations, should maximize their profit has long been a basic tenet of economics and remains the dominant paradigm of the corporate finance literature (Shleifer-Vishny (1997)). That profit maximization by large firms exploiting their market power typically leads to lower production and higher prices than optimal has not changed the view that profit should be maximized, but rather has led to the adoption of laws restricting the behavior of large corporations. ${ }^{1}$ The message of this paper is that even if these laws and the associated agencies created to implement them are successful in enforcing competition on the product and labor markets, and even if a corporation does not create standard direct externalities, profit maximization is still not a socially optimal objective. For corporations, like all businesses, operate in an environment of uncertainty and the success or failure of a large corporation may have a significant impact not only on its shareholders, but also on the consumers it serves and on the workers it employs. This, as we show, creates a form of externality which is present as soon as non-negligible firms make investment decisions which influence the likelihood of success or failure of their stochastic technologies.

To explore this idea we consider a setting where a firm's investment has a positive probability of improving the firm's technology - the greater the investment the greater the probability of success - but the technological improvement is specific to the firm, and does not affect other firms' technologies. The potential improvement can be viewed as a "firm-specific innovation"it has the characteristic of a process innovation, since with some probability it decreases the marginal cost of production, but does not have the spillover or knowledge effect which has been the focus of the growth literature and the literature on innovation. Examples of such firm-specific innovations would be the restructuring of a company, improvements in the technology or design of its product or, in the other direction, investment expenditures on quality, maintenance, and control procedures to minimize the risk of adverse technological outcomes.

In this setting we study whether the profit motive leads to an efficient choice of investment. To focus on the kernel of the argument, in much of the paper we study a "benchmark" model in which there is a single firm exposed to risk and a competitive fringe which is a stand-in for the rest of the production sector. The firm is "non-negligible" in the sense that the prices on the product and labor markets differ depending on whether the 'good' or the 'bad' technology is realized: thus the firm is sufficiently large to have "market impact". It is clear that if, once the technology is realized, the firm decides to exploit its market power in its choice of labor (output) on the spot markets, then there will be inefficiency due to oligopolistic pricing. Since from a theoretical perspective it is useful to distinguish between the different sources of imperfection due to the presence of large firms, in most of the paper we factor out this latter source of inefficiency by assuming that all firms act as price takers on the product and labor markets.

This permits us to identify a novel source of inefficiency for a non-negligible profit-maximizing firm. Since investment by the firm shifts probability to the outcome where it is more productive, reducing the expected price of its output and increasing the expected wage of its employees, the firm's investment influences the expected utilities of consumers and workers: maximizing

\footnotetext{
${ }^{1}$ Antitrust Law in the US, Competition Law in Europe and the agencies charged with their enforcement, like the Federal Trade Commission and the European Commission.
} 
expected profit does not internalize the effect of the investment on the expected utilities of consumers and workers, so that "shareholder value maximization" is not the correct "social criterion" and leads to systematic underinvestment by the firm. The inefficiency can be attributed to a form of pecuniary externality of the firm's investment: increasing investment changes expected prices and wages and, at a profit maximizing equilibrium, the increased cost of investment equals the increase in the firm's expected profit on the spot markets, but is less than the increase in expected total surplus.

The presence of externalities brings to mind the use of government taxes and subsidies as a corrective device. Indeed Greenwald-Stiglitz (1986) have presented a general equilibrium framework for studying Pareto improving taxes (subsidies) in the presence of either technological or pecuniary externalities. In our setting a subsidy to the firm's investment would improve on the shareholder equilibrium: however we argue that the internal nature of the investment and the possible improvements to which it leads make it difficult for a regulator to have sufficient information to subsidize exactly the type of expenses that would reduce the risks of adverse outcomes or improve the productive efficiency of the firm. Assuming that agents close to the firm - the shareholders, the consumers and certainly the workers - have better information than a regulator about the costs and possible improvements to the technology of a company, it seems natural to study whether the firm can be led to internalize the externality by including the interests of consumers and workers into the criterion it uses for its choice of investment.

In Section 4 we study the behavior of a stakeholder firm that maximizes the sum of the surpluses of its shareholders, consumers and workers. We show that if the firm can be considered independently of other firms - for example if it is a "natural monopoly" - then the stakeholder objective leads to a socially optimal investment. The main problem is then to obtain information on the surpluses of consumers and workers. We suggest that implementing the Coasian approach of creating marketable rights, "consumer rights" or the right to buy from the firm, and "worker rights" or the right to work for the firm, can serve to elicit these surpluses and provide a measurable way of evaluating the performance of the stakeholder firm.

When there are several firms competing on the same product and labor markets, if a stakeholder firm were to maximize the sum of the surpluses of its own stakeholders, it would exaggerate the difference in benefit between the good and the bad outcome, and would be led to over-invest to make the successful outcome more likely. For such a calculation would exclude the stakeholders of competing firms who are also affected by the firm's outcome, and their interests are at odds with those of the stakeholders of the firm under consideration. Thus there is under-investment when only profit is taken into account, and over-investment if the total surplus of its own stakeholders is used as the firm's criterion. However if we introduce a "stakeholder oriented" firm that puts most of the weight on its shareholder value but also gives a small positive weight to consumer and worker surpluses, the resulting equilibrium outcome improves on the shareholder equilibrium.

Relation to the Literature. Our success/failure model has a number of different interpretations. If the implicit reference point is the 'bad' or costly technology then the model can be viewed as a model of innovation. There are however important differences with the models of 
innovation in the IO and macro growth literature ${ }^{2}$. First, we consider firm-specific innovations, which do not have spillover effects on other firms: patents are irrelevant for such innovations. Second most of the innovation literature assumes that firms operate with constant marginal cost so that monopolistic profit guaranteed by a patent is necessary to cover the research cost and provide the incentive to innovate. By contrast, we assume that firms behave competitively and have technologies with decreasing marginal returns. ${ }^{3}$ Third, unlike most of the IO literature, we adopt a general equilibrium approach that permits us to relate our results to the Arrow-Debreu welfare theorems, and also serve to clarify that innovation, even firm-specific, generates externalities not only on consumers but also on workers, through general equilibrium effects on labor markets.

If in the 'bad' outcome the firm does not operate (i.e. has zero output) while in the 'good' outcome it is productive, and if the probability chosen by the firm is either zero or one, then the model is a model of entry akin to the competitive version of Mankiw-Whinston (1986). Although our model focuses more on the investment of an existing firm rather than the entry of a new firm into a market, our under-investment result corresponds to the insufficient entry result in the competitive version of Mankiw-Whinston.

On the other hand if the implicit reference point is the 'good' technology, then investment serves to decrease the likelihood of the adverse outcome in which the firm ends up with the bad technology. The investment refers to expenditures on quality control, maintenance and design procedures and other risk control procedures which seek to reduce the probability of malfunction or design flaws. To our knowledge little attention has been given to the view that the profit motive does not induce large corporate enterprises to spend enough to avoid the occurrence of adverse outcomes that can have a significant negative impact on economic agents beyond its shareholders. ${ }^{4}$

Organization of paper. Section 2 introduces the benchmark model and the concept of a shareholder equilibrium in which firms use the criterion of profit maximization: it shows that there is always under-investment in a shareholder equilibrium. Possible ways of resolving the inefficiency of investment are discussed in Section 3, while Section 4 examines the idea of using a stakeholder approach to resolve the problem of under-investment in a shareholder equilibrium. Section 5 concludes.

\section{Inefficiency of Shareholder Equilibrium}

Consider a two-period stochastic production economy with a finite number of firms. There are three goods: a produced good, a composite good called "money" (used as the numeraire)

\footnotetext{
${ }^{2}$ See Tirole (1998), Aghion-Howitt (1998), Acemoglu (2009) for excellent surveys of this literature.

${ }^{3}$ The model of endogenous growth of Hellwig-Irmen (2001) also assumes competitive markets and decreasing returns. In their model firms are negligible but their innovations automatically enter (with a delay of one period) into the general technological knowledge of the economy. Since these future benefits cannot be priced in a market and hence do not enter the profit of an innovating firm, there is also under-investment in their competitive equilibrium.

${ }^{4}$ An exception is Allen-Carletti-Marquez (2011) which is motivated by the cost incurred by workers who are laid off when a firm goes bankrupt. They study how the pricing strategy of a "stakeholder firm", which takes into account in its objective function the cost of layoffs for its workers, differs from that of a "shareholder firm" maximizing profit.
} 
and labor. At date 0 the only available resource is money, a part of which can be used to finance investment expenditures by the firms. Each firm faces production risk and operates in an environment where its projects can be more or less successful. While a firm cannot completely control its environment it can invest resources to increase the probability of better outcomes. To keep the analysis simple we assume that each firm $j=1, \ldots, J$ has two possible ${ }^{5}$ outcomes at date 1 , a good technology $f_{g}^{j}$ or a less productive technology $f_{b}^{j}$, and that incurring expenditures $\gamma^{j}$ can augment the probability $\pi^{j}$ of the good outcome $f_{g}^{j}$. Our objective is to study whether the standard criterion of profit maximization by firms leads to socially optimal choices $\left(\gamma^{1}, \ldots, \gamma^{J}\right)$ or if some other criterion may be required.

\subsection{Benchmark Model}

In the benchmark model only firm 1 is subject to risk and all other firms can be summarized by a surrogate second firm ${ }^{6}$ with deterministic technology $\hat{f}$. At date 1 the first firm's technology will be one of the two production functions $y_{s}=f_{s}(l)$ where $s$ is either $g$ or $b$. Each production function $f_{s}: \mathbb{R}_{+} \rightarrow \mathbb{R}_{+}$is differentiable, increasing, concave and satisfies $f_{s}(0)=0, s=g, b$. The marginal product of $f_{g}$ is uniformly higher than that of $f_{b}: f_{g}^{\prime}(l)>f_{b}^{\prime}(l), \forall l>0$, which implies that $f_{g}(l)>f_{b}(l), \forall l>0$, thus justifying the terminology that $g$ is the good and $b$ the bad outcome. By choosing its investment expenditure at date 0 , firm 1 determines the probability $\pi$ of having the good outcome at date 1 . The cost of investment is a function $\gamma(\pi)$ of the probability $\pi$, where $\gamma:[0,1) \rightarrow \mathbb{R}+$ is differentiable, increasing, strictly convex, and satisfies $\gamma(0)=\gamma^{\prime}(0)=0, \gamma^{\prime}(\pi) \rightarrow \infty$ as $\pi \rightarrow 1$. To retain the symmetry of notation, we let $\pi_{s}$ denote the probability of outcome $s, s=g, b$, with $\pi_{g}=\pi$ and $\pi_{b}=1-\pi$. Firm 2 does not face risk and makes no investment at date 0 . It operates a technology $\hat{f}(\hat{l})$ at date 1 where $\hat{f}$ is differentiable, increasing, concave and satisfies $\hat{f}(0)=0$. To avoid boundary solutions we assume that all production functions satisfy the Inada condition $f_{g}^{\prime}(0)=f_{b}^{\prime}(0)=\hat{f}^{\prime}(0)=\infty$.

There are three "classes" of agents: workers/employees, consumers, and finally capitalists/shareholders. Within each class there is a continuum of identical agents of mass 1 . Each worker is endowed with 1 unit of labor at date 1, consumes only money and has the utility function

$$
U^{w}(m, \ell)=m_{0}+\delta \sum_{s=g, b} \pi_{s}\left(m_{s}-v\left(\ell_{s}\right)\right)
$$

where $m=\left(m_{0}, m_{g}, m_{b}\right)$ is a worker's consumption of money and $\ell_{s}$ is the quantity of labor sold to the firm in outcome $s, s=g, b$. The discount factor satisfies $0<\delta \leq 1$ and the disutility of labor, $v(\ell): \mathbb{R}_{+} \rightarrow \mathbb{R}$, is differentiable, convex and increasing, with $v(0)=0, v^{\prime}(0)=0$ and $v^{\prime}(\ell) \rightarrow \infty$ if $\ell \rightarrow 1$. Throughout we will use the symbol " $\ell$ " for the labor supplied by the representative worker and " $l$ " for the demand for labor by the firms.

Each consumer, who consumes both money and the produced good, has the utility function

$$
U^{c}(m, c)=m_{0}+\delta \sum_{s=g, b} \pi_{s}\left(m_{s}+u\left(c_{s}\right)\right),
$$

\footnotetext{
${ }^{5}$ The analysis can be extended to a finite number of outcomes: this makes the analytical expressions more complex, but does not change the fundamental nature of the insights we obtain.

${ }^{6}$ This is without loss of generality if all firms other than firm 1 are not subject to risk.
} 
where $c=\left(c_{g}, c_{b}\right)$ is the consumption of the produced good in the two outcomes, and $u$ is differentiable, strictly concave and increasing, with $u(0)=0$ and $u^{\prime}(c) \rightarrow \infty$ if $c \rightarrow 0$.

Finally there are capitalists (shareholders), who own the firms, consume only money and have the same (linear) utility function

$$
U^{k}(m)=m_{0}+\delta \sum_{s=g, b} \pi_{s} m_{s}
$$

For reasons that we explain later, we assume that the two firms are owned by distinct subsets of shareholders. The money endowments $e^{i}=\left(e_{0}^{i}, e_{1}^{i}\right), i=w, c, k$ are assumed to be sufficiently large so that non-negativity constraints on consumption never bind. We let $e_{0}=e_{0}^{w}+e_{0}^{c}+e_{0}^{k}$, $e_{1}=e_{1}^{w}+e_{1}^{c}+e_{1}^{k}$ denote the aggregate endowments of money at date 0 and 1 , and denote by $\mathcal{E}=(U, e, f, \gamma, \hat{f})$ the economy with preferences and endowments $\left(U^{i}, e^{i}\right)_{i=w, c, k}$ and technologies $(f, \gamma, \hat{f})$ for the firms.

\subsection{Socially Optimal Investment}

Given the quasi-linearity of the agents' preferences, a Pareto optimum is an allocation ${ }^{7}$ $\left(\pi^{*}, m^{*}, c^{*}, \ell^{*}, l^{*}, \hat{l}^{*}\right)$ that maximizes the sum of the agents' utilities

$$
\max _{(\pi, m, c, \ell, l, \hat{l}) \geq 0} \sum_{i=w, c, k}\left(m_{0}^{i}+\delta \sum_{s=g, b} \pi_{s} m_{s}^{i}\right)+\delta \sum_{s=g, b} \pi_{s}\left[u\left(c_{s}\right)-v\left(\ell_{s}\right)\right]
$$

subject to the resource constraints for money, consumption and labor

$$
\begin{aligned}
& \sum_{i=w, c, k} m_{0}^{i}+\gamma(\pi)=e_{0}, \quad \sum_{i=w, c, k} m_{s}^{i}=e_{1}, \\
& c_{s}=f_{s}\left(l_{s}\right)+\hat{f}\left(\hat{l}_{s}\right), \quad \ell_{s}=l_{s}+\hat{l}_{s}, \quad s=g, b .
\end{aligned}
$$

This is equivalent to finding $\left(c^{*}, \ell^{*}, \pi^{*}, l^{*}, \hat{l}^{*}\right)$ that solves

$$
\left.\max _{(c, \ell, \pi, l, \hat{l}) \geq 0} e_{0}-\gamma(\pi)+\delta \sum_{s=g, b} \pi_{s}\left[e_{1}+u\left(c_{s}\right)\right)-v\left(\ell_{s}\right)\right]
$$

subject to the resource constraints (1). The maximum problem (2) decomposes into the choice, in each outcome $s=g, b$ (at date 1 ) of consumption-labor allocations $\left(c_{s}^{*}, \ell_{s}^{*}, l_{s}^{*}, \hat{l}_{s}^{*}\right)$ that maximize social welfare

$$
W_{s}=u\left(c_{s}\right)-v\left(\ell_{s}\right)
$$

subject to the resources constraints (1), and firm 1's choice of investment (at date 0) or more directly the choice of the probability of success $\pi^{*}$ that maximizes

$$
\delta\left(\pi W_{g}^{*}+(1-\pi) W_{b}^{*}\right)-\gamma(\pi)
$$

\footnotetext{
${ }^{7}$ We use the following notational convention: a letter without superscript or subscript summarizes the vector of indexed values of the corresponding variable. For example, $m=\left(\left(m_{0}^{i}, m_{s}^{i}\right), i=w, c, k, s=g, b\right)$ and $\ell=\left(\ell_{s}\right)_{s=g, b}$
} 
where $W_{g}^{*}, W_{b}^{*}$ are the optimized values of (3). The first-order conditions for the choice of consumption-labor at date 1 are, for $s=g, b$ :

$$
u^{\prime}\left(c_{s}^{*}\right) f_{s}^{\prime}\left(l_{s}^{*}\right)=u^{\prime}\left(c_{s}^{*}\right) \hat{f}^{\prime}\left(\hat{l}_{s}^{*}\right)=v^{\prime}\left(\ell_{s}^{*}\right), \quad c_{s}^{*}=f_{s}\left(l_{s}^{*}\right)+\hat{f}\left(\hat{l}_{s}^{*}\right), \quad \ell_{s}^{*}=l_{s}^{*}+\hat{l}_{s}^{*}
$$

Since the social welfare $W_{s}$ in each outcome $s$ is a strictly concave function, there is a unique solution to the FOCs (5), which are necessary and sufficient for characterizing the optimal allocation. Since $f_{g}(l)>f_{b}(l)$ for all $l>0, W_{g}(l, \hat{l})=u\left(f_{g}(l)+\hat{f}(\hat{l})\right)-v(l+\hat{l})>u\left(f_{b}(l)+\right.$ $\hat{f}(\hat{l}))-v(l+\hat{l})=W_{b}(l, \hat{l})$ so that $W_{g}^{*}=\max _{(l, \hat{l})} W_{g}(l, \hat{l})>W_{b}^{*}=\max _{(l, \hat{l})} W_{b}(l, \hat{l})$. Again, this justifies our notation that " $\mathrm{g}$ " is indeed the good social outcome. The FOC for the optimal choice of investment by firm 1 at date 0 is given by

$$
\delta\left(W_{g}^{*}-W_{b}^{*}\right)=\gamma^{\prime}\left(\pi^{*}\right),
$$

and this has a unique solution $\pi^{*}$ since $\gamma^{\prime}$ increases from 0 to $\infty$. (6) requires that the marginal cost of increasing the probability of success equals the discounted social benefit of realizing the good rather than the bad outcome of firm 1.

\subsection{Shareholder Equilibrium}

Consider a market equilibrium of the above economy assuming that both firms make their choices in the best interests of their shareholders: both make a labor decision at date 1, and firm 1 in addition makes an investment choice at date 0 . Consumers buy the firms' output and workers sell their labor services on spot markets; the agents can also trade on asset markets to redistribute their income. We show that the real side of such a market equilibrium can be summarized by a vector $(\bar{\pi}, \bar{l}, \overline{\hat{l}})$ consisting of the probability of the good outcome, and the labor choices in each technology outcome. This vector can then be compared with the Pareto optimal choice $\left(\pi^{*}, l^{*}, \hat{l}^{*}\right)$ derived above.

At each date the price of the composite commodity (money) is normalized to 1 . At date 0 agents trade a riskless bond promising one unit of money in each outcome $s=g, b$ at date 1

with price $\frac{1}{1+r}$ where $r$ is the interest rate. There is also an equity market at date 0 on which the agents trade the shares of the firms, the price of equity being $q$ for firm 1 and $\hat{q}$ for firm 2 . At date 1 for each outcome $s=g, b$ there are spot markets for labor and the produced good with prices $\left(w_{s}, p_{s}\right), s=g, b$. Since the date 1 payoff of the bond is $(1,1)$, and the payoffs of the shares of firm 1 are different in the two outcomes $s=g, b$, the bond and firm 1's equity have linearly independent payoff streams, so that the financial markets are complete with respect to the uncertainty $g, b$.

Firm 1 makes two types of choices: at date 0 it selects its investment expenditure which determines the probability $\pi$ of its 'good' outcome and at date 1 it chooses the amount of labor $l=\left(l_{g}, l_{b}\right)$ to hire when the technology is realized. Since the firm is not infinitesimal (see Section 2.5 for a discussion of that case) the spot prices $\left(w_{s}, p_{s}\right)$ depend on its outcome, and we assume that the firm recognizes that it has "market impact". If at date 1 the firm acts strategically in its choice of labor (output) knowing the elasticities of the demand for its product and the supply of labor, then we say that it exploits its "market power" on the spot markets. If it makes its choice of labor taking prices as given, then we say it acts competitively 
on the spot markets. There are two potential sources of inefficiency in the model, one, that we exhibit below, arising from the choice of investment, the other arising from monopoly/oligopoly pricing on the spot markets. The first is new, the second familiar. For the purpose of theory it is useful to distinguish the two imperfections, and our model permits the distinction to be made. In this section we assume that firm 1 behaves competitively on the spot market and chooses its labor $l_{s}$ in each outcome to maximize its profit $R_{s}\left(l_{s} ; w_{s}, p_{s}\right)=p_{s} f_{s}\left(l_{s}\right)-w_{s} l_{s}$, taking the spot prices $\left(w_{s}, p_{s}\right)$ as given. In Section 3 we discuss what happens when firms also exert their market power through prices as well as investment decisions.

Assuming that the firm correctly anticipates the spot prices and its future labor decision, it chooses the probability $\pi$ at date 0 to maximize the (net) present value of profit, which in this case is just the discounted expected profit net of the investment cost since agents are risk neutral. Firm 1's combined choice problem amounts to choosing $(\pi, l)$ to maximize its value for the shareholders, which we denote by SV:

$$
S V(\pi, l ; w, p)=\sum_{s=g, b} \frac{\pi_{s}}{1+r} R_{s}\left(l_{s} ; w_{s}, p_{s}\right)-\gamma(\pi) .
$$

In the same way firm 2 , which has no date 0 investment decision, maximizes its value for the shareholders

$$
\widehat{S V}(\hat{l} ; w, p)=\sum_{s=g, b} \frac{\pi_{s}}{1+r} \hat{R}\left(\hat{l}_{s} ; w_{s}, p_{s}\right),
$$

by choosing $\hat{l}_{s}$ at date 1 which maximizes its profit $\hat{R}\left(\hat{l}_{s} ; w_{s}, p_{s}\right)=p_{s} \hat{f}\left(\hat{l}_{s}\right)-w_{s} \hat{l}_{s}$.

The three groups of agents trade on the spot and financial markets and have sequential budget equations at date 0 and in each outcome at date 1 of the form

$$
\begin{aligned}
& m_{0}^{i}=e_{0}^{i}-\frac{1}{1+r} z^{i}-q \theta^{i}-\hat{q} \hat{\theta}^{i}+\xi^{i} \\
& m_{s}^{i}=e_{s}^{i}+z^{i}+R_{s} \theta^{i}+\hat{R}_{s} \hat{\theta}^{i}+w_{s} \ell_{s}^{i}-p_{s} c_{s}^{i}, \quad s=g, b
\end{aligned}
$$

where $z^{i}$ is the bond holding and $\theta^{i}, \hat{\theta}^{i}$ are the ownership shares of the firms purchased by agent $i$. Finally

$$
\begin{aligned}
& \text { - } \quad \xi^{i}=0, \quad \text { if } i=w, c, \quad \xi^{i}=[q-\gamma(\pi)] \theta_{0}^{i}+\hat{q} \hat{\theta}_{0}^{i} \quad \text { if } i=k \\
& \text { - } c_{s}^{i}=0, \quad \text { if } i=w, k, \quad c_{s}^{i}=c_{s} \quad \text { if } i=c \\
& \text { - } \ell_{s}^{i}=0, \quad \text { if } i=c, k, \quad \ell_{s}^{i}=\ell_{s} \quad \text { if } i=w,
\end{aligned}
$$

where $\theta_{0}^{i}$ and $\hat{\theta}_{0}^{i}$ denote the initial shareholdings of capitalist $i$ (these sum to one across $i$ and cannot both be positive since the firms are owned by distinct subsets of individuals). The owners of firm 1 finance the cost $\gamma(\pi)$ proportionally to their (initial) shares of firm 1 and all capitalists get income from the sale of their initial shareholdings $\xi^{i}=[q-\gamma(\pi)] \theta_{0}^{i}+\hat{q} \hat{\theta}_{0}^{i}$. While shareholders are assumed to finance the investment of firm 1, any mode of financing, whether by debt or by issuing new shares, would lead to the same equilibrium in view of the Modigliani-Miller theorem. Only the consumers purchase the produced good $\left(c_{s}^{c}=c_{s}\right)$ and only workers sell their labor services $\left(\ell_{s}^{w}=\ell_{s}\right)$. All agents are assumed to know firm 1's choice 
of $\pi$ at date 0 and to correctly anticipate future spot prices and the firms' profits $R_{s}$ and $\hat{R}_{s}$ in each outcome $s$ at date 1 .

Given the linearity of the agents' preferences in the numeraire composite commodity, the first-order conditions for the optimal choice of bond and equity holdings imply

$$
\frac{1}{1+r}=\delta, \quad q=\delta \sum_{s=g, b} \pi_{s} R_{s}=\sum_{s=g, b} \frac{\pi_{s}}{1+r} R_{s}, \quad \hat{q}=\sum_{s=g, b} \frac{\pi_{s}}{1+r} \hat{R}_{s}
$$

so that pricing is risk neutral. Since financial markets are complete, the sequential budget constraints (9) are equivalent to the single intertemporal (present value) budget constraint

$$
m_{0}^{i}+\sum_{s=g, b} \frac{\pi_{s}}{1+r} m_{s}^{i}=e_{0}^{i}+\frac{e_{1}^{i}}{1+r}+\xi^{i}+\sum_{s=g, b} \frac{\pi_{s}}{1+r}\left(w_{s} \ell_{s}^{i}-p_{s} c_{s}^{i}\right), \quad i=w, c, k
$$

where $\left(\xi^{i}, c^{i}, \ell^{i}\right)$ are given by (10). In view of the linearity of the agents' preferences in $m^{i}=$ $\left(m_{0}^{i}, m_{g}^{i}, m_{b}^{i}\right)$ any $m^{i}$ satisfying $(12)$ is equivalent for agent $i$, and when the budget constraint (12) is satisfied, the utility of agent $i$ is

$$
\begin{array}{ll}
\text { - } e_{0}^{w}+\frac{e_{1}^{w}}{1+r}+\sum_{s=g, b} \frac{\pi_{s}}{1+r}\left(w_{s} \ell_{s}-v\left(\ell_{s}\right)\right) & \text { for a worker } \\
\text { - } e_{0}^{c}+\frac{e_{1}^{c}}{1+r}+\sum_{s=g, b} \frac{\pi_{s}}{1+r}\left(u\left(c_{s}\right)-p_{s} c_{s}\right) & \text { for a consumer } \\
\text { - } e_{0}^{k}+\frac{e_{1}^{k}}{1+r}+[q-\gamma(\pi)] \theta_{0}^{i}+\hat{q} \hat{\theta}_{0}^{i} & \text { for a capitalist }
\end{array}
$$

Thus a worker will choose $\ell$ to maximize 13(a), a consumer will choose $c$ to maximize 13(b) and a capitalist has no other choice than to spend his income on the composite good. If he is among the owners of firm $1\left(\hat{\theta}_{0}^{i}=0\right)$ then his utility is maximized when firm 1 maximizes its shareholder value $S V=q-\gamma(\pi)$, and if he is among the owners of firm $2\left(\theta_{0}^{i}=0\right)$ then his utility is maximized when firm 2 maximizes its shareholder value $\widehat{S V}=\hat{q} .{ }^{8}$

Summing the budget equations (12), assuming that (10) holds, gives

$$
\sum_{i=w, c, k} m_{0}^{i}+\sum_{s=g, b} \frac{\pi_{s}}{1+r} m_{s}^{i}=e_{0}+\frac{e_{1}}{1+r}+q+\hat{q}-\gamma(\pi)+\sum_{s=g, b} \frac{\pi_{s}}{1+r}\left(-p_{s} c_{s}+w_{s} \ell_{s}\right)
$$

If the markets clear for the produced good $\left(c_{s}=f_{s}\left(l_{s}\right)+\hat{f}\left(\hat{l}_{s}\right)\right)$ and labor $\left(\ell_{s}=l_{s}+\hat{l}_{s}\right)$ then in view of (11) the terms involving the firm's market value cancel out, giving

$$
\sum_{i=w, c, k} m_{0}^{i}+\sum_{s=g, b} \frac{\pi_{s}}{1+r} m_{s}^{i}=e_{0}+\frac{e_{1}}{1+r}-\gamma(\pi) .
$$

\footnotetext{
${ }^{8}$ Our assumption that the two firms are owned by distinct subsets of shareholders simplifies the analysis. It implies that each firm maximizes its own shareholder value. Our results would still hold for different ownership structures but the investment choice of firm one would have to take into account the externalities it exerts on firm two.
} 
Given the indeterminacy in the choice of $m^{i}$, we can assume that when agents choose $m^{i}$ to satisfy (12) they in addition choose money holdings such that

$$
\sum_{i=w, c, k} m_{0}^{i}+\gamma(\pi)=e_{0}, \quad \sum_{i=w, c, k} m_{s}^{i}=e_{1}, \quad s=g, b
$$

so that the market for the composite good clears at date 0 and in each outcome $s$ at date 1 .

Since our objective is to compare the consumption, labor and investment choices which arise in a market equilibrium with those at the social optimum, we focus directly on a succinct reduced-form definition of an equilibrium involving these three choices. From this reduced-form equilibrium a complete description of the equilibrium on the spot markets for the produced good, money and labor, and on the financial markets for the bond and equity can readily be reconstructed using (9)-(11) and (14).

Definition 1. A (reduced-form) shareholder equilibrium of the economy $\mathcal{E}$ is a vector of actions and prices $((\bar{\ell}, \bar{c}, \bar{\pi}, \bar{l}, \overline{\hat{l}}),(\bar{w}, \bar{p}))$ such that

(i) the labor choice $\bar{\ell}=\left(\bar{\ell}_{g}, \bar{\ell}_{b}\right) \geq 0$ maximizes worker's utility 13(a) given $\bar{w}$;

(ii) the consumption choice $\bar{c}=\left(\bar{c}_{g}, \bar{c}_{b}\right) \geq 0$ maximizes consumer's utility 13 (b) given $\bar{p}$;

(iii) firm 1's production plan $(\bar{\pi}, \bar{l})=\left(\bar{\pi}, \bar{l}_{g}, \bar{l}_{b}\right) \geq 0$ maximizes shareholder value $(7)$ given $(\bar{w}, \bar{p}) ;$

(iv) firm 2's production plan $(\overline{\hat{l}})=\left(\overline{\hat{l}}_{g}, \overline{\hat{l}}_{b}\right) \geq 0$ maximizes shareholder value $(8)$ given $(\bar{w}, \bar{p})$;

(v) the markets clear: $\bar{\ell}_{s}=\bar{l}_{s}+\overline{\hat{l}}_{s}, \quad \bar{c}_{s}=f_{s}\left(\bar{l}_{s}\right)+\hat{f}\left(\overline{\hat{l}}_{s}\right), \quad s=g, b$.

Let us compare the FOCs for the maximum problems (i)-(iv) of a shareholder equilibrium with the FOCs for a Pareto optimum. In a shareholder equilibrium the optimal labor choice $\bar{\ell}$ for the workers satisfies

$$
v^{\prime}\left(\bar{\ell}_{s}\right)=\bar{w}_{s}, \quad s=g, b
$$

and the consumers' optimal choice $\bar{c}$ satisfies

$$
u^{\prime}\left(\bar{c}_{s}\right)=\bar{p}_{s}, \quad s=g, b
$$

while the firm's profit-maximizing choices of labor $(\bar{l}, \overline{\hat{l}})$ imply that for each outcome at date 1 the real wage equals the marginal product of labor

$$
\bar{p}_{s} f_{s}^{\prime}\left(\bar{l}_{s}\right)=\bar{w}_{s}, \quad \bar{p}_{s} \hat{f}^{\prime}\left(\overline{\hat{l}}_{s}\right)=\bar{w}_{s} \quad s=g, b .
$$

Using (15), (16) to eliminate spot prices and adding the market clearing condition (v) gives the equations, for $s=g, b$ :

$$
u^{\prime}\left(\bar{c}_{s}\right) f_{s}^{\prime}\left(\bar{l}_{s}\right)=u^{\prime}\left(\bar{c}_{s}\right) \hat{f}^{\prime}\left(\overline{\hat{l}}_{s}\right)=v^{\prime}\left(\bar{\ell}_{s}\right), \quad \bar{c}_{s}=f\left(\bar{l}_{s}\right)+\hat{f}(\overline{\hat{l}}), \quad \bar{\ell}_{s}=\bar{l}_{s}+\overline{\hat{l}}_{s},
$$


which characterize the spot market equilibrium at date 1 . Since (18) is identical to (5), which characterizes the maximum of the social welfare, the choice of labor in equilibrium is optimal and

$$
(\bar{c}, \bar{\ell}, \bar{l}, \overline{\hat{l}})=\left(c^{*}, \ell^{*}, l^{*}, \hat{l}^{*}\right) .
$$

The remaining first-order condition for the choice of investment $\bar{\pi}$ which maximizes shareholder value $(7)$ is

$$
\frac{1}{1+r}\left(\bar{R}_{g}-\bar{R}_{b}\right)=\gamma^{\prime}(\bar{\pi}) \text { if } \bar{R}_{g}>\bar{R}_{b}, \quad \bar{\pi}=0 \text { otherwise }
$$

where $\bar{R}_{s}$ is the maximized profit of firm 1 in outcome $s$ : this equation has a unique solution since $\gamma^{\prime}(\pi)$ increases from 0 to $\infty$. Comparing (19) with (6) we see that if $W_{g}^{*}-W_{b}^{*}>\bar{R}_{g}-\bar{R}_{b}$ then $\bar{\pi}<\pi^{*}$ since $\gamma^{\prime}$ is increasing: the profit criterion underestimates the social gain from obtaining the technology $f_{g}$ rather than the technology $f_{b}$.

Proposition 1. There is under-investment in the shareholder equilibrium: $\bar{\pi}<\pi^{*}$.

Proof: Lemma 1 in the Appendix proves the property $W_{g}^{*}-W_{b}^{*}>\bar{R}_{g}-\bar{R}_{b}$, from which the result follows.

The proof is based on the simple intuition of what happens when the technology of firm 1 moves from its 'bad' technology to its 'good' technology. A first consequence of this move is that labor moves out of firm 2, but the increased productivity of firm 1 may lead to either an increase or a decrease in its demand for labor. Thus the total labor employed by the two firms (and hence the wage) may either increase or decrease. It is easy to deduce from the the proof of Lemma 1 in the Appendix that, when moving from state $b$ to state $g$ :

(i) the sum of the surpluses of consumers of firms 1 and 2 increases

(ii) the sum of the surpluses of workers of firms 1 and 2 may increase ${ }^{9}$ or decrease, depending on the curvatures of the functions $\left(u, v, f_{g}, f_{b}, \hat{f}\right)$

(iii) the profit of firm 2 decreases: improving the competitor's technology hurts the shareholders of firm 2 .

For $s=g, b$, the difference $W_{s}^{*}-\bar{R}_{s}$ is the sum of the surpluses in (i)-(iii). The surprising part of the proof of Lemma 1 is that despite the ambiguity of the sign of (ii) and the negative sign of (iii), the sum of these surpluses increases in moving from $b$ to $g: W_{b}^{*}-\bar{R}_{b}<W_{g}^{*}-\bar{R}_{g}$. By the Hicks-Kaldor criterion, even though there may be some losers from the improvement in firm 1's technology, the winners can compensate the losers. The difference $\left[W_{g}^{*}-W_{b}^{*}\right]-\left[\bar{R}_{g}-\bar{R}_{b}\right]$ measures precisely the pecuniary externality created by firm 1's investment at date 0 .

The inefficiency of a shareholder equilibrium comes from the fact that firm 1's investment affects all agents in the economy, not just its shareholders. Since the welfare of the consumers,

\footnotetext{
${ }^{9}$ Workers are better off if total labor employed increases: this occurs when the elasticity of demand is sufficiently small. In the extreme case where $u$ is linear, the price of the output does not change $\left(\bar{p}_{g}=\bar{p}_{b}\right)$ and the consumers have no surplus: all improvement in technology goes to increasing the wages of the workers.
} 
workers and shareholders of firm 2 is different in outcomes $g$ and $b$, the choice of $\pi$ affects their expected utilities. In a shareholder equilibrium firm 1 chooses its investment only taking into account the effect on its expected profit (the welfare of its shareholders) and ignores the effect of its investment on all other groups of agents: the profit criterion fails to "internalize" the externality of its action on agents other than its shareholders. ${ }^{10}$

\subsection{General Model with $J$ Firms}

The underinvestment result of Proposition 1 applies to a setting in which a dominant firm (firm 1) operates on spot markets for labor and output in parallel with a competitive fringe (represented by $\hat{f}$ ). We now extend this result to the more general setting where there are $J$ firms, each of which makes an investment choice relative to its risky technology. In the general case where the $J$ firms face different risks and have access to different technologies we can show, by comparing first-order conditions, that a shareholder equilibrium is not Pareto optimal. But the under-investment result of Proposition 1 is no longer always true. However when the firms are sufficiently similar - in short when we appeal to symmetry - the under-investment result can be extended to the case of $J$ firms.

To keep notation simple we focus on the case where $J=2$ and assume that the second firm now has a technology that is exposed to risk: if it invests $\hat{\gamma}(\hat{\pi})$ at date 0 it will use the technology $\hat{f}_{g}$ with probability $\hat{\pi}$ and the technology $\hat{f}_{b}$ with probability $1-\hat{\pi}$. We assume in addition that $\left(\hat{f}_{g}, \hat{f}_{b}\right)=\left(f_{g}, f_{b}\right)$ and $\hat{\gamma}(\hat{\pi})=\gamma(\pi)$ (the symmetry assumption). There are now four possible outcomes $s=\left(s_{1}, s_{2}\right)$, with $s_{1} \in\{g, b\}$ and $s_{2} \in\{g, b\}$. We assume that the risks to which the firms are exposed are independent so that the probability of the outcome $s=\left(s_{1}, s_{2}\right)$ is $\pi_{s}=\pi_{s_{1}} \hat{\pi}_{s_{2}}$. With this change in the definition of the outcome $s$, finding a Pareto optimal allocation still consists in finding a solution to (2) subject to the resource constraint (1) where firm 2's production function is now indexed by $s\left(\hat{f}_{s}=\hat{f}_{g}\right.$ if $s_{2}=g, \hat{f}_{s}=\hat{f}_{b}$ if $\left.s_{2}=b\right)$. As in the benchmark model the analysis can be decomposed into two steps: the first consists in finding the consumption-labor decision $\left(c_{s}^{*}, \ell_{s}^{*}, l_{s}^{*}, \hat{l}_{s}^{*}\right)$ which maximizes the social welfare $W_{s}=u\left(c_{s}\right)-v\left(\ell_{s}\right)$ for each $s$; the second consists in finding the optimal investments $\left(\pi^{*}, \hat{\pi}^{*}\right)$ which maximize the expected discounted welfare net of the cost of investment. The solution of the first problem is, as before, characterized by $(5)$ where $\left(\hat{f}, \hat{f}^{\prime}\right)$ is replaced by $\left(\hat{f}_{s}, \hat{f}_{s}^{\prime}\right)$. On the other hand the first-order conditions for the two firms socially optimal investment choices $\left(\pi^{*}, \hat{\pi}^{*}\right)$ are now characterized by the pair of equations

$$
\begin{aligned}
& \left(W_{g g}^{*}-W_{b g}^{*}\right) \hat{\pi}^{*}+\left(W_{g b}^{*}-W_{b b}^{*}\right)\left(1-\hat{\pi}^{*}\right)=\frac{1}{\delta} \gamma^{\prime}\left(\pi^{*}\right) \\
& \left(W_{g g}^{*}-W_{g b}^{*}\right) \pi^{*}+\left(W_{b g}^{*}-W_{b b}^{*}\right)\left(1-\pi^{*}\right)=\frac{1}{\delta} \hat{\gamma}^{\prime}\left(\hat{\pi}^{*}\right)
\end{aligned}
$$

where $W_{s}^{*}$ denotes the optimized social welfare in outcome $s \in \mathcal{S}$. (20) is the generalization of (6) to the case where both firms make investment decisions at date 0 . When the two firms

\footnotetext{
${ }^{10}$ The inefficiency result does not rely on the assumption of quasi-linear preferences. This assumption just allows a much simpler analysis of consumer and employee surplus when we analyse the stakeholder model. The generic inefficiency result in the general case with wealth effects is in Magill and Quinzii (2009). Basically, they show that the first order conditions characterizing the equilibrium behavior of shareholder value maximizing firms are distinct from the ones that characterize Pareto Optimality. This is much easier to see in the quasi-linear case, but is true more generally.
} 
have the same risks and the same technology, the first-order condition for the symmetric Pareto optimal investment $\pi^{*}$ reduces to the single equation

$$
\left(W_{g g}^{*}-W_{b g}^{*}\right) \pi^{*}+\left(W_{g b}^{*}-W_{b b}^{*}\right)\left(1-\pi^{*}\right)=\frac{1}{\delta} \gamma^{\prime}\left(\pi^{*}\right)
$$

The increments in social welfare have the following intuitive submodularity property which serves to establish the uniqueness of the symmetric Pareto optimum.

Lemma $2 W_{g b}^{*}-W_{b b}^{*}>W_{g g}^{*}-W_{b g}^{*}>0$.

Lemma 2, whose proof is given in the Appendix, asserts that the increment in social welfare when firm 1 has a good rather than a bad outcome is greater when the other firm has the outcome "b" rather than "g", since firm 1 adds its production to the smaller production by firm 2. The existence and uniqueness of a symmetric Pareto optimum follows at once by noting that the function

$$
\phi(\pi)=\left(W_{g g}^{*}-W_{b g}^{*}\right) \pi+\left(W_{g b}^{*}-W_{b b}^{*}\right)(1-\pi)-\frac{1}{\delta} \gamma^{\prime}(\pi)
$$

satisfies $\phi(0)>0, \phi(\pi) \rightarrow-\infty$ as $\pi \rightarrow 1$, and $\phi^{\prime}(\pi)<0$ by Lemma 2 and $\gamma^{\prime \prime}>0$. Since $\phi$ is continuous there is a unique $\pi^{*}$ satisfying $\phi\left(\pi^{*}\right)=0$.

The concept of a (reduced-form) shareholder equilibrium (Definition 1) extends in an natural way to this new setting where both firms have risks: the maximum problem of firm 2 ((iv) in Definition 1) now involves choosing a probability $\hat{\pi}$ at date 0 and a production plan in each outcome $s \in \mathcal{S}$ at date 1 . As before profit maximization and optimal choices of consumers and workers on spot markets at date 1 lead to an optimal consumption-labor allocation for each outcome $s \in \mathcal{S}$. The first-order conditions for the optimal choices of investment $(\bar{\pi}, \overline{\hat{\pi}})$ by the firms which maximize shareholder values are given by

$$
\begin{aligned}
& \left(\bar{R}_{g g}^{1}-\bar{R}_{b g}^{1}\right) \overline{\hat{\pi}}+\left(\bar{R}_{g b}^{1}-\bar{R}_{b b}^{1}\right)(1-\overline{\hat{\pi}}) \leq \frac{1}{\delta} \gamma^{\prime}(\bar{\pi}),=\text { if } \bar{\pi}>0 \\
& \left(\bar{R}_{g g}^{2}-\bar{R}_{g b}^{2}\right) \bar{\pi}+\left(\bar{R}_{b g}^{2}-\bar{R}_{b b}^{2}\right)(1-\bar{\pi}) \leq \frac{1}{\delta} \hat{\gamma}^{\prime}(\overline{\hat{\pi}}),=\text { if } \overline{\hat{\pi}}>0
\end{aligned}
$$

where $\bar{R}_{s}^{1}$ and $\bar{R}_{s}^{2}$ denote the maximized profit of firms 1 and 2 given the spot prices $\left(\bar{p}_{s}, \bar{w}_{s}\right)$. (22) is the generalization of (19) to the setting were both firms make investment decisions at date 0 . At a symmetric equilibrium $\bar{R}_{b g}^{1}=\bar{R}_{g b}^{2}, \bar{R}_{g g}^{1}=\bar{R}_{g g}^{2}, \bar{R}_{b b}^{1}=\bar{R}_{b b}^{2}$ so that the common choice of investment, which for simplicity we still denote by $\bar{\pi}$, is characterized by the FOC

$$
\left(\bar{R}_{g g}^{1}-\bar{R}_{b g}^{1}\right) \bar{\pi}+\left(\bar{R}_{g b}^{1}-\bar{R}_{b b}^{1}\right)(1-\bar{\pi}) \leq \frac{1}{\delta} \gamma^{\prime}(\bar{\pi}),=\text { if } \bar{\pi}>0 .
$$

Establishing a monotone ranking of the solutions of the first-order conditions (20) at a Pareto optimum and at an equilibrium (22) in the general case $^{11}$ is difficult: however when the firms are similar the submodularity property makes it is possible to compare the solutions of $(21)$ and (23) and this leads to the following generalization of Proposition 1.

\footnotetext{
${ }^{11}$ Existence of a shareholder equilibrium is easy to establish under our assumption of two productive outcomes per firm. For an existence result when there are more than two outcomes, see Magill and Quinzii (2009).
} 
Proposition 2. In any symmetric shareholder equilibrium of an economy with $J$ firms there is under-investment: $\bar{\pi}<\pi^{*}$.

Proof: The proof of Proposition 1 consisted in showing that $W_{g}^{*}-W_{b}^{*}>\bar{R}_{g}-\bar{R}_{b}$ when firm 2 has a fixed technology. This implies that for any realization of the technology of firm 2

$$
W_{g s_{2}}^{*}-W_{b s_{2}}^{*}>\bar{R}_{g s_{2}}^{1}-\bar{R}_{b s_{2}}^{1}, \quad s_{2}=g, b
$$

We want to prove that $\bar{\pi}<\pi^{*}$. Suppose by contradiction that $\bar{\pi} \geq \pi^{*}$. Since $\pi^{*}$ is positive, this implies that $\bar{\pi}>0$, and thus that (23) holds with equality. Then $\gamma^{\prime}(\bar{\pi}) \geq \gamma^{\prime}\left(\pi^{*}\right)$ and by (21) and (23)

$$
\begin{aligned}
\left(\bar{R}_{g g}^{1}-\bar{R}_{b g}^{1}\right) \bar{\pi}+\left(\bar{R}_{g b}^{1}-\bar{R}_{b b}^{1}\right)(1-\bar{\pi}) & \geq\left(W_{g g}^{*}-W_{g b}^{*}\right) \pi^{*}+\left(W_{b g}^{*}-W_{b b}^{*}\right)\left(1-\pi^{*}\right) \\
& \geq\left(W_{g g}^{*}-W_{g b}^{*}\right) \bar{\pi}+\left(W_{b g}^{*}-W_{b b}^{*}\right)(1-\bar{\pi})
\end{aligned}
$$

where the second inequality follows from Lemma 2: the convex combination with weights $(\bar{\pi}$, $1-\bar{\pi})$ puts less weight on the larger term $\left(W_{b g}^{*}-W_{b b}^{*}\right)$ than the convex combination with weights $\left(\pi^{*}, 1-\pi^{*}\right)$. The resulting inequality between expected profit and expected welfare increments contradicts (24): thus $\bar{\pi}<\pi^{*}$. The proof is readily extended to the case $J>2$ and is left to the reader.

\subsection{Continuum of Firms}

There is a way of changing the structure of our economy to obtain an equilibrium with profitmaximizing firms which is Pareto optimal: it suffices to replace the finite set of $J$ firms by a continuum of firms. ${ }^{12}$ More precisely, consider a modified economy with a continuum of ex-ante identical firms, where each firm makes an investment at date 0 which influences the probability of its outcome $f_{g}$ or $f_{b}$ at date 1 . If each firm's outcome is independent of the outcomes of the other firms and all firms choose the same probability $\pi$, then by an (appropriate variant) of the Law of Large Numbers a proportion $\pi$ of firms will produce with $f_{g}$, a proportion $1-\pi$ will produce with $f_{b}$, and the average output produced and the spot prices will be non random. It is easy to show that a symmetric shareholder equilibrium exists in which each firm's investment maximizes the present value of its profit and the equilibrium investment is Pareto optimal (see the Internet Appendix).

However in this modified model, which is elegant and well behaved from a theoretical point of view, a firm has been transformed into an infinitesimal entity, far removed from the large corporate firm that we seek to model: the infinitesimal firms that populate this economy aptly fit what Berle and Means (1932) in their classic study described as the small sole proprietorships originally envisaged by Adam Smith. As they argued with great clarity, such firms have little or nothing in common with the large corporate firms whose securities are traded on the stock market and which, even in their day, had come to have a significant footprint on the economic landscape. ${ }^{13}$

\footnotetext{
${ }^{12}$ Beginning with Prescott and Townsend (1984a and b) models with a continuum of firms have been widely used to explore equilibria with moral hazard. See e.g. Bisin-Gottardi (1999), Lisboa (2001), Zame (2007) and Acemoglu-Simsek (2010) for models of this type.

13 "When Adam Smith talked of "enterprise" he had in mind as the typical unit the small individual firm in
} 


\section{$3 \quad$ Seeking Solutions to Inefficiency}

Section 2 presented a model in which firms make investment decisions that influence the success or failure of their future uncertain technologies. Propositions 1 and 2 asserted that if investment is chosen to maximize profit then firms are led to underinvest: a firm's investment has an external effect which is not internalized by the profit criterion. One may wonder if the externality is simply an artifact of the way the market equilibrium has been modeled. The standard way of incorporating uncertainty in general equilibrium is to use the ArrowDebreu (AD) model with states of nature which are primitive causes whose probabilities are exogenously given and are not influenced by the actions of economic agents. This is different from the modeling of this paper where there is a fixed finite number of outcomes $(g$ and $b$ for the benchmark model) whose probabilities are influenced by the firm's investment. It is this dependence that creates the externality on agents' expected utilities. ${ }^{14}$ However in the Arrow-Debreu model, since the probabilities of the states of nature are exogenous there is no externality of a firm's actions on agents' expected utilities. Could the externality be removed by replacing the shareholder equilibrium by the Arrow-Debreu equilibrium of our economy?

\subsection{Arrow-Debreu Equilibrium of Benchmark Economy}

In the Internet Appendix we show how our benchmark model can be embedded in an ArrowDebreu model by introducing states of nature $(\omega \in \Omega)$ and a production function $F(\omega, \gamma, l)$ such that the set of states $\omega \in \Omega$ for which $F(\omega, \gamma, l)=f_{g}(l)$ has probability $\pi_{g}(\gamma)$ and the set of states for which $F(\omega, \gamma, l)=f_{b}(l)$ has probability $\pi_{b}(\gamma)$. We study the Arrow-Debreu equilibrium of the economy and show that

(i) the assumption that firm 1 takes the prices of output and labor $(p(\omega), w(\omega))$ as given in each state of nature $(\omega \in \Omega)$ is incompatible with the assumption that the firm has correct (rational) expectations;

(ii) an Arrow-Debreu equilibrium does not exist. This comes from the fact that modeling the success/failure uncertainty using the state of nature approach leads to a non-convex production set.

The intuition for these results is easy to obtain in the case where production does not involve labor, i.e. when $f_{g}(l)=y_{g}, f_{b}(l)=y_{b}, v(l)=0$ for all $l \geq 0$. The only possible level of investment at an $\mathrm{AD}$ equilibrium is the efficient level $\pi^{*}$. However assuming that firm 1 's profit is maximal at $\pi^{*}$ leads to a contradiction. In the AD equilibrium the firm is assumed to act as if the spot price was exogenously determined by the abstract state of nature $\omega$ and is independent of its investment decision. If the firm considers a marginal increase $\Delta \pi$ above $\pi^{*}$, then its outcome will be $y_{g}$ in some states where it is $y_{b}$ with $\pi^{*}$. The AD price-taking assumption is that the price stays at $p_{b}$ in these states despite the fact that the supply of the consumption good has changed by a non negligible amount. This is what we mean in (i) when we say that

which the owner perhaps with the aid of a few ... workers, labored to produce goods for market. ... These units have been supplanted ... by great aggregations in which tens or even hundreds of thousands of workers and property ... belonging to tens or even hundred of thousands of individuals are combined through the corporate mechanism into a single producing organization under unified control", Berle and Means (1932, pp.4 \& 303).

${ }^{14}$ See Magill-Quinzii (2009) for a discussion of the two approaches. 
the $\mathrm{AD}$ price taking assumption is incompatible with the assumption of correct expectations. It turns out that this assumption also leads to the non-existence of an equilibrium. For the change in investment entails an increase in expected discounted revenue of $\Delta R^{+}=\delta p_{b}\left(y_{g}-y_{b}\right) \Delta \pi$. If profit is maximum at $\pi^{*}$, it must be that $\left.\delta p_{b}\left(y_{g}-y_{b}\right) \leq \gamma^{\prime *}\right)$, so that an increase in investment does not increase the (expected discounted) profit. But then a marginal decrease $\Delta \pi<0$ below $\pi^{*}$ will entail a decrease in discounted revenue $\Delta R^{-}=\delta p_{g}\left(y_{b}-y_{g}\right)(-\Delta \pi)$. This decrease in investment is worthwhile since $p_{g}<p_{b}$ implies $\left.\delta p_{g}\left(y_{g}-y_{b}\right)<\delta p_{b}\left(y_{g}-y_{b}\right) \leq \gamma^{*}\right)$. Thus $\pi^{*}$ can not maximize the discounted expected profit of firm 1 and an AD equilibrium does not exist. $^{15}$

The simple stochastic two-outcome (or more generally finite-outcome) economy falls into the class of stochastic economies mentioned by Arrow (1971) for which no Arrow-Debreu equilibrium exists due to the inherent non-convexity of the production set when translated to the state-of-nature setting. ${ }^{16}$ And yet this success/failure type of uncertainty with the probability of success influenced by some action on the part of the firm is a common and pervasive type of uncertainty. To use the Arrow Debreu model in such a setting would require the assumption of a continuum of firms to take advantage of the convexifying effect of large numbers. This would solve problem (ii) above. It would also imply that all firms are negligible, solving problem (i) but eliminating the very problem we want to study. In contrast the probability model and the concept of a shareholder equilibrium presented in Section 2 are compatible with non-negligible firms having market impact and permits the presence of market impact to be distinguished from the use of market power. Factoring out market power on prices enables us to retain much of the simplicity of the competitive model - in particular we can treat consumers and workers symmetrically, which is difficult to do in traditional IO models.

\subsection{Classical Remedies for Externalities}

Since the externality cannot be removed by resorting to the concept of an Arrow-Debreu equilibrium, let us return to the benchmark model and explore ways in which the inefficiency exhibited in Propositions 1 and 2 can be alleviated. This externality is not standard. In the classification of externalities suggested by Laffont (1989) it is of the type "firms on consumers (and workers)" whereas the externality of the innovation literature is of the type "firms on firms". It goes through agents's preferences, which explicitly depend on the probabilities $\pi_{s}$

\footnotetext{
${ }^{15}$ Another illustration of the problems associated with using the concept of $\mathrm{AD}$ equilibrium in our context is given by the entry model of Mankiw-Whinston (1986), which can be viewed as a particular case of our model. The shareholder equilibrium concept is the same as the one used by Mankiw and Whinston: firms decide to enter or not, based on the profit $\pi^{*}(N)$ they anticipate as a function of the number $N$ of active firms, and of the type of competition that prevails. If firms are price takers, we obtain the competitive entry model. The equilibrium number of firms is the maximum number $N^{*}$ such that $\pi^{*}(N)$ exceeds the entry cost $\gamma$. In the AD version, each firm would assume that the price is independent of the number of firms that enter, and would take as given the equilibrium profit $\pi^{*}\left(N^{*}\right)$. Thus the $\mathrm{AD}$ equilibrium would only exist when $\gamma$ is precisely equal to $\pi^{*}\left(N^{*}\right)$ for some integer $N^{*}$. This is clearly non-generic.

... it is possible to set up formal mechanisms which under certain conditions will achieve an optimal allocation of risk by competitive methods. However, the empirical validity of the conditions for the optimal character of competitive allocation is considerably less likely to be fulfilled in the case of uncertainty. (Arrow, 1971)
} 
of productive outcomes, probabilities that are chosen by the firms. However it is akin to a pecuniary externality ${ }^{17}$ since productive outcomes determine equilibrium prices and wages. The common element with the innovation literature is that investment creates a positive externality which is not internalized by standard profit maximizing behavior and typically leads to underinvestment. It is thus instructive to examine if the remedies proposed for attenuating the externality in the IO/growth literature could help in our setting. The innovation literature basically recommends two types of policy for increasing investment expenditure on research on new technologies: first, assigning a patent to an innovating firm giving it a property right to its innovation, and second, subsidizing research. Since in our model the success or failure of the firm does not affect the technologies of other firms, there is no free-rider problem associated with other firms copying the innovation without sharing the cost, so that a patent is not applicable. However if we think of a patent as a formal device for encouraging firms to exploit their market power to increase the profit they get from the innovation then it has an interesting parallel with our model.

For if instead of earning the competitive profit on the spot markets firm 1 (in the benchmark model) earns greater profit by exploiting its market power, then the higher profit may provide a greater incentive to invest. This is certainly true in the case where the firm is a monopoly $(\hat{f} \equiv 0)$ and $f_{b} \equiv 0, f_{g}>0$ since the difference in monopoly profit between the good and the bad outcome $\left(R_{g}^{m}-0\right)$ is greater than the difference in competitive profit $\left(\bar{R}_{g}-0\right)$ so that investment is greater with monopoly profit in view of (19). However there is still under-investment since the monopoly profit does not capture all the surplus. In the more general case where $\hat{f}>0$ and $f_{b}>0$ it becomes harder to compare the difference in oligopoly and competitive profits, with the additional difficulty that the oligopoly profit depends on the nature of the imperfect competition that is assumed to take place between the firms on the spot market. What is sure is that investment will not be optimal since generically $W_{g}^{*}-W_{b}^{*} \neq R_{g}^{\nu}-R_{b}^{\nu}$ where $\nu$ denotes the nature of the imperfect competition between the firms on the spot markets. Counting on imperfect competition to alleviate the under-investment is not however a satisfactory way to proceed, since the decrease in welfare on the spot markets may exceed the gain (when it exists) from the increased investment. It would be better to find a way of simultaneously alleviating the inefficiencies created by the externality and the imperfectly competitive pricing rather than counting on one inefficiency to offset the other.

The other way of alleviating under-investment, advocated in the innovation/growth literature is to subsidize research. In our model subsidizing the investment expenditure $\gamma$ of firm 1 and financing the subsidy with lump-sum taxes on the agents could resolve the inefficiency. However the "firm-specificity" of the investment makes it unlikely that this solution can be implemented in practice. If we think of the investment as decreasing the probability of a "bad" outcome, the expenses involved could consist of increasing the labor devoted to maintenance,

\footnotetext{
${ }^{17}$ However it is different from the two categories of pecuniary externalities that have been identified in the literature. It does not rely on the spanning role of prices in incomplete markets like in Geanakoplos and Polemarchakis (1986), because preferences are quasi linear and risk sharing considerations are absent. It does not rely either on the second category of pecuniary externalities, identified by Greenwald and Stiglitz (1986) where prices enter agents's decisions problems beyond their budget constraints through information asymmetries. Here the mechanism is different: a (non-negligible) firm's investment decision affects prices in goods and labor markets, and thus indirectly impacts the welfare of consumers and workers.
} 
quality control, production control, or could consist of using more expensive inputs which make it more likely to obtain a satisfactory output. It would be difficult for an outside agency to distinguish these expenses from the ordinary expenses associated with production and to subsidize them. In the same way expenses in management time to better organize the firm, and even in research and development inside the firm to improve its production processes - all expenses which make a "good" outcome more likely - would be difficult to separate from standard production expenses. In the case of research with possible spillovers the subsidies take the form of financing 'fundamental research' by the government in universities and government agencies. The second stage of research which is carried out inside firms, to go from the basic research to industrial applications is generally not subsidized, ${ }^{18}$ in large part because of the same problem of non observability. To formalize this difficulty arising from the non-observability, which gives rise to moral hazard problems when subsidies are involved, we can assume that the investment $\gamma(\pi)$ of Firm 1, although observable by the shareholders, consumers and employees of the firm, is not observable by an outside government agency.

\section{Stakeholder Approach}

In the previous section we argued that the remedies proposed in the innovation literature for solving the externality problem do not seem appropriate for solving the problem of underinvestment in our setting. Three approaches have been proposed for correcting inefficiencies created by the presence of externalities: ${ }^{19}$ (i) outside intervention either by government (through regulation or Pigouvian taxes/subsidies) or by the judicial system (in the form of civil tort laws implemented by courts); (ii) internal solutions such as mergers (integration of all the parties involved in the externality); (iii) market solutions, for example by creating Coasian securities i.e. tradeable property rights associated with the externality (Coase, 1960). Although (i) may be appropriate in some settings ${ }^{20}$ since in our model the externality principally affects agents directly related to the operations of the firm - its consumers, its workers and its shareholderswho are de facto natural stakeholders, it seems worthwhile to explore an "internal solution" in which the firm merges the interests of all its stakeholders.

The idea that a large corporation should take into account the interests of all its stakeholders is not new, but has mainly been discussed outside the economic literature - with the notable exception of Tirole $(2001,2006) .{ }^{21}$ As Tirole (2001) makes clear, it has not been precisely articulated in the framework of a formalized model and this may serve to explain why it has not been extensively discussed in the economic literature. Let us explore how our model

\footnotetext{
${ }^{18} \mathrm{It}$ is at this point that the patent system typically takes over from subsidization.

${ }^{19}$ See for example the discussion in Laffont (1989).

${ }^{20}$ For example, Blanchard-Tirole (2001) propose introducing a tax on workers' layoffs aimed at inducing firms to internalize the externalities inflicted on laid-off workers. In their model the externality comes from frictions in the labor market.

${ }^{21}$ Tirole (2001) defines corporate governance "as the design of institutions that induce or force management to internalize the welfare of stakeholders..." in order to internalize a broad array of externalities. We do not seek to develop a theory encompassing all types of externalities that can be created by large firms: our contribution is rather to identify a new form of externality that seems to have been overlooked, and to suggest ways to correct it. Such an externality exists as soon as a firm is non-negligible and takes actions that influence the probability of its outcomes, even without any frictions in labor and consumption markets.
} 
suggests formalizing a stakeholder theory and whether such an approach can restore efficiency.

\subsection{Single Firm: Stakeholder Equilibrium}

We begin with the simplest version of the benchmark model $\left(f_{s}, \hat{f}\right)$ in which $\hat{f}=0$, i.e. there is a single firm which makes an investment a date 0 and uses labor to produce output at date 1. Let $((\bar{\pi}, \bar{l}),(\bar{w}, \bar{p}))$ denote the shareholder equilibrium in this case. We saw that $\bar{l}_{s}=l_{s}^{*}$, where $l_{s}^{*}$ is the labor choice which maximizes the social welfare $W_{s}^{*}=\max _{l \geq 0}\left\{u\left(f_{s}\left(l_{s}\right)\right)-v\left(l_{s}\right)\right\}$ : spot markets allocate labor efficiently in each outcome $s$ at date 1 and the social welfare in equilibrium $\bar{W}_{s}$ is the maximum welfare $W_{s}^{*}$. The inefficiency comes from the investment choice $\bar{\pi}$ at date 0 which is characterized by the FOC for profit maximization

$$
\frac{1}{1+r}\left(\bar{R}_{g}-\bar{R}_{b}\right)=\gamma^{\prime}(\bar{\pi})
$$

whereas the socially optimal investment $\pi^{*}$ is characterized by

$$
\frac{1}{1+r}\left(\bar{W}_{g}-\bar{W}_{b}\right)=\gamma^{\prime}\left(\pi^{*}\right)
$$

Given spot prices $\left(w_{s}, p_{s}\right)$ the consumer and worker surpluses are defined by

$$
C S_{s}\left(p_{s}\right)=\max _{c_{s} \geq 0}\left\{u\left(c_{s}\right)-p_{s} c_{s}\right\} \quad W S_{s}\left(w_{s}\right)=\max _{\ell_{s} \geq 0}\left\{w_{s} \ell_{s}-v\left(\ell_{s}\right)\right\}
$$

Since $u(0)=0$ and $v(0)=0, C S_{s}\left(p_{s}\right)$ is the net gain in utility for the representative consumer from being able to buy the good at price $p_{s}$, while $W S_{s}\left(w_{s}\right)$ is the net utility gain for the representative worker from being able to sell labor at the wage $w_{s}$. When, as in the shareholder equilibrium, agents trade on spot markets at prices $\left(\bar{w}_{s}, \bar{p}_{s}\right)$ and markets clear $\left(\bar{l}_{s}=\bar{\ell}_{s}\right)$ the social welfare in outcome $s$ can be expressed as

$$
\begin{aligned}
\overline{W_{s}} & =u\left(\bar{c}_{s}\right)-v\left(\bar{\ell}_{s}\right)=\left(u\left(\bar{c}_{s}\right)-\bar{p}_{s} \bar{c}_{s}\right)+\left(\bar{w}_{s} \bar{\ell}_{s}-v\left(\bar{\ell}_{s}\right)\right)+\left(\bar{p}_{s} f_{s}\left(\bar{l}_{s}\right)-\bar{w}_{s} \bar{l}_{s}\right) \\
& =\overline{C S}_{s}+\overline{W S}_{s}+\bar{R}_{s}
\end{aligned}
$$

namely as the sum of consumer surplus, worker surplus, and shareholder profit. As we saw in Proposition 1 the inefficiency of investment in a shareholder equilibrium comes from the property that $\bar{W}_{g}-\bar{W}_{b}>\bar{R}_{g}-\bar{R}_{b}$. The difference comes from the sum of the two terms $\overline{C S}_{g}-\overline{C S}_{b}$ and $\overline{W S}_{g}-\overline{W S}_{b}$, the difference in consumer and worker surplus between the good and the bad outcome, which measures precisely the external effect which is not internalized by the firm when it uses the present value of profit as its criterion for the choice of investment. Thus to obtain a stakeholder criterion for the firm which ensures that the effect of its investment decision is fully internalized, the firm needs to take into account not only its shareholders but also the consumers it serves and the workers it employs since these latter two parties also gain from having the good rather than the bad outcome.

Proposition 4. Consider the case with only one active firm. If in the concept of equilibrium we replace the criterion of maximizing shareholder value by maximizing the total surplus of 
the stakeholders

$$
\frac{1}{1+r} \sum_{s=g, b} \pi_{s}\left(C S\left(\bar{p}_{s}\right)+W S\left(\bar{w}_{s}\right)+R_{s}\left(\bar{w}_{s}, \bar{p}_{s}\right)\right)-\gamma(\pi)
$$

then we obtain a stakeholder equilibrium $\left(\left(\pi^{*}, \bar{l}\right),(\bar{w}, \bar{p})\right)$ which is Pareto optimal.

Another important consequence arises from the adoption of the total surplus criterion (26): the assumption that the equilibrium prices on the spot market are the "competitive" prices $\left(\bar{w}_{s}, \bar{p}_{s}\right), s=g, b$ is no longer needed-it is a byproduct of the criterion. A monopoly maximizing the total surplus will choose $l_{s}=l_{s}^{*}$ since this maximizes the surplus in outcome $s$ - a necessary condition for maximizing expected total surplus (26) - and thus will set the prices at $\left(\bar{w}_{s}, \bar{p}_{s}\right), s=g, b$. When the welfare of all stakeholders is taken into account there is no reason to exploit the elasticity of demand for the product or of the supply of labor to increase the profit of the shareholders. Thus in the monopoly case the stakeholder criterion solves both the problem of "market power" and the problem of "market impact".

\subsection{Coasian Approach}

Although criterion (26) provides a precise definition of the stakeholders' interests, it does not guarantee that the criterion can or will be used as the basis of decision making by the firm's manager: ways of measuring the "surpluses" CS and WS, as well as incentives for the management to maximize (26), must also exist. Thus the implementation of a stakeholder equilibrium raises three issues ${ }^{22}$ :

- Incentives: incentives must be given to the firm's manager to apply the stakeholder criterion.

- Information : to apply the stakeholder criterion the manager needs information on the characteristics of the consumers and workers to evaluate their surpluses.

- Financing: if the shareholder value at the stakeholder equilibrium is negative, an additional source of funds beyond equity and debt must be found, since otherwise the shareholders would dispose of their ownership shares rather than being forced to finance a project with a negative net present value.

Since markets are typically good at providing both incentives and information, can we imagine a way to use markets that would provide the appropriate incentives and information to maximize the sum of the surpluses in (26), leaving aside for the moment the problem of financing? In the spirit of Coase (1960) we introduce the idea that creating explicit tradeable property rights associated with the externalities created by the firm may provide the extension of the markets required to implement a stakeholder equilibrium. ${ }^{23}$

\footnotetext{
${ }^{22}$ See Tirole (2001) for a discussion of these issues.

${ }^{23}$ When all agents are identical and simultaneously consumers, workers and shareholders, the externalities can be internalized by giving identical equity shares to all agents, since they will all agree that the firm should maximize the welfare of the representative agent as in Morgan-Tumlinson (2012). In our model where consumers, workers and shareholders have different preferences, there is no way of distributing equity shares among the agents that leads to the Pareto optimal investment. In a model with imperfect competition and two distinct
} 
Suppose therefore that at date 0 , in addition to the market for equity on which ownership shares are traded, there is a market for "consumer rights" — or more briefly c-rights — on which agents exchange the right to buy the good produced by the firm at date 1 at the spot price $p=\left(p_{g}, p_{b}\right)$. In addition there is a market for "worker rights" - or more briefly w-rights - on which agents exchange the right to sell labor to the firm at date 1 at the spot price $w=\left(w_{g}, w_{b}\right)$. Suppose every consumer has an endowment of one c-right and every worker as an endowment of one w-right. To understand how the market values these rights we need to create some scarcity by assuming that only a mass $1-\varepsilon$ of consumers and workers is endowed with rights and then let $\varepsilon$ go to zero.

A worker with no initial w-right who observes the investment decision $\gamma(\pi)$ and anticipates a date 1 wage $w=\left(w_{g}, w_{b}\right)$ would be willing to pay up to

$$
W V(\pi, w)=\delta\left[\pi W S_{g}\left(w_{g}\right)+(1-\pi) W S_{b}\left(w_{b}\right)\right]
$$

to obtain the right to work for the firm, where $W S\left(w_{s}\right)$ defined by $(25)$ is the surplus utility that a worker derives from selling labor at the wage $w_{s}: W V(\pi, w)$ is the date 0 "worker value" of being employed by the firm. A worker who owns a w-right will accept to sell it if its price is equal to or exceeds (27). Thus if $\varepsilon>0$, equilibrium on the market for w-rights occurs at the price

$$
q_{w}(\pi, w)=W V(\pi, w)
$$

If $\varepsilon=0$ and every worker is endowed with a w-right, then no worker needs to buy a right, so that any price between 0 and $q_{w}(\pi, w)$ (at which every worker wants to keep the initial w-right) is an equilibrium price. To retain the symmetry of the model we assume that every worker is endowed with a w-right and that the market price of a w-right is given by (28), since any scarcity, no matter how small, will immediately force the price to $q_{w}(\pi, w)$. By a similar argument, the market price $q_{c}(\pi, p)$ of a c-right is taken to be the discounted expected surplus utility derived by a consumer from buying the produced good at price $p$ from the firm, namely the "consumer value" $C V(\pi, p)$

$$
q_{c}(\pi, p)=C V(\pi, p)=\delta\left(\pi C S_{g}\left(p_{g}\right)+(1-\pi) C S_{b}\left(p_{b}\right)\right)
$$

With the market valuations (28) and (29) in hand we now have a way of implementing a stakeholder equilibrium. If the firm's manager chooses labor at date 1 and the probability $\pi$ at date 0 to maximize the total market value of the rights of its stakeholders,net of the cost of investment

$$
q_{w}(\pi, \hat{w})+q_{c}(\pi, \hat{p})+q_{e}(\pi, \hat{w}, \hat{p})-\gamma(\pi) .
$$

Then the firm's criterion for choosing investment coincides with the total surplus criterion (26) of a stakeholder equilibrium and leads to the socially optimal investment decision $\pi^{*}$.

The advantage of having an explicit market for w-rights and c-rights in addition to equity is that the firm's manager maximizes an objective, observable market value rather than an

classes of agents Demichelis and Ritzberger (2011) show that efficient pricing decisions can be obtained if agents trade equity shares strategically, being aware that their ability to influence the firm's decision depends on the magnitude of their ownership share. 
unobservable surplus. However to provide the manager with the incentive to maximize the stakeholder value (30), workers and consumers must be able to influence the investment decision of the firm. Thus when w-rights and c-rights are issued by the firm, the owners of these rights acquire legal voting rights in the decision making process for investment. If unanimity is required to approve a change of management, then the management will maximize the net stakeholder value (30) or be replaced: for if a manager fails to maximize (30), a "raider" could choose an investment with a higher stakeholder value and in the process transfer enough value to workers, consumers and shareholders to buy their votes. In addition to providing the manager with incentives to apply the stakeholder criterion, the existence of markets for w-rights and c-rights provides the required information on the worker and consumer surpluses: knowledge of the price functions $q_{w}(\pi, \hat{w})$ and $q_{c}(\pi, \hat{p})$, which may be acquired from repeated observations of market prices, is sufficient information to be able to maximize the total surplus in the economy. ${ }^{24}$

In the above analysis we assumed that the w-rights and c-rights had already been issued. Thus neither consumers nor workers contribute to the funding of the firm's investment which must be paid by the shareholders, either directly as assumed in Section 2, or indirectly through the issue of bonds, which is equivalent. Such financing is possible only if $q_{e}\left(\pi^{*}, \hat{w}, \hat{p}\right) \geq \gamma\left(\pi^{*}\right)$. Otherwise the shareholders will prefer to dispose of their equity shares rather than finance a project with a negative net present value. If $q_{e}\left(\pi^{*}, \hat{w}, \hat{p}\right)<\gamma\left(\pi^{*}\right)$, the stakeholder equilibrium can still be implemented through stakeholder value maximization, provided that the model is taken at the stage where the firm issues the rights. Since by assumption the optimal expected total surplus is positive

$$
\pi^{*} W_{g}^{*}+\left(1-\pi^{*}\right) W_{b}^{*}-\gamma\left(\pi^{*}\right)>0
$$

the net market value of these surpluses is positive

$$
q_{w}\left(\pi^{*}, \hat{w}\right)+q_{c}\left(\pi^{*}, \hat{p}\right)+q_{e}\left(\pi^{*}, \hat{w}, \hat{p}\right)-\gamma\left(\pi^{*}\right)>0 .
$$

If the firm issues the rights and chooses $\pi^{*}$ to maximize the market value of the rights plus the net profit, then the proceeds $q_{w}\left(\pi^{*}, \hat{w}\right)+q_{c}\left(\pi^{*}, \hat{p}\right)$ from the sale of the rights is sufficient to ensure that the shareholder value is positive since (31) can be written as

$$
q_{e}\left(\pi^{*}, \hat{w}, \hat{p}\right)-\left(\gamma\left(\pi^{*}\right)-q_{w}\left(\pi^{*}, \hat{w}\right)+q_{c}\left(\pi^{*}, \hat{p}\right)\right)>0
$$

Thus the issue of rights can resolve the problem of financing when the net expected profit at the optimal investment is negative. ${ }^{25}$

\footnotetext{
${ }^{24}$ The Internet Appendix to this paper contains an extension of our model that incorporates the possibility of moral hazard on the part of the manager. It shows that, since the pledgeable income (in the sense of Tirole (2001)) is reduced by the necessity of paying higher bonuses to the manager, the firm may have more difficulty financing its investment, unless consumers and/or workers participate in the financing (see next footnote).

${ }^{25}$ This is corroborated by Michelacci and Quadrini $(2005,2009)$, who argue that employees sometimes participate in the financing of their firms. They provide empirical evidence that some firms initially pay their employees below the market wage and above market wages after some years. They interpret this finding along the lines suggested here: credit constrained firms may find it optimal to borrow from their employees.
} 


\subsection{Multi-firm: Stakeholder Oriented Equilibrium}

Let us see how the above analysis can be extended to the benchmark model $(f, \hat{f})$ with $\hat{f} \neq 0$, where the firm that has the risky investment must compete with other firms on the labor and product markets. This simple setting suffices to illustrate the difficulties with extending a stakeholder theory to the multi-firm case.

To begin the analysis let us assume that each firm maximizes its profit on the spot markets taking prices as given as in Section 2. The labor is allocated efficiently on the spot markets and the efficient level of investment is obtained if firm 1 chooses $\pi$ to maximize the social welfare $\delta\left(\pi W_{g}^{*}+(1-\pi) W_{b}^{*}\right)-\gamma(\pi)=\delta\left(\pi \bar{W}_{g}+(1-\pi) \bar{W}_{b}\right)-\gamma(\pi)$, where $\bar{W}_{s}=u\left(f_{s}\left(\bar{l}_{s}\right)+\hat{f}\left(\hat{l}_{s}\right)\right)-v\left(\bar{l}_{s}+\overline{\hat{l}}_{s}\right)$, and where $\bar{l}_{s}, \overline{\hat{l}}_{s}$ are the profit maximizing choices of labor at the price $\bar{p}_{s}=u^{\prime}\left(f_{s}\left(\bar{l}_{s}\right)+\hat{f}\left(\overline{\hat{l}}_{s}\right)\right)$ and wage $\bar{w}_{s}=v^{\prime}\left(\bar{l}_{s}+\overline{\hat{l}}_{s}\right)$. Using the notation $\bar{y}_{s}=f_{s}\left(\bar{l}_{s}\right)$ and $\overline{\hat{y}}_{s}=\hat{f}\left(\overline{\hat{l}}_{s}\right)$ the social welfare in outcome $s$ can be decomposed as

$$
\begin{aligned}
\bar{W}_{s} & =\left(u\left(\bar{y}_{s}+\overline{\hat{y}}_{s}\right)-\bar{p}_{s}\left(\bar{y}_{s}+\overline{\hat{y}}_{s}\right)\right)+\left(\bar{w}_{s}\left(\bar{l}_{s}+\overline{\hat{l}}_{s}\right)-v\left(\bar{l}_{s}+\overline{\hat{l}}_{s}\right)\right)+\left(\bar{p}_{s}\left(\bar{y}_{s}+\overline{\hat{y}}_{s}\right)-\bar{w}_{s}\left(\bar{l}_{s}+\overline{\hat{l}}_{s}\right)\right) \\
& =\overline{C S}_{s}+\overline{W S}_{s}+\bar{R}_{s}+\overline{\hat{R}}_{s},
\end{aligned}
$$

where the surplus terms can be further decomposed as

$$
\begin{aligned}
\overline{C S}_{s} & =\left(\left[u\left(\bar{y}_{s}+\overline{\hat{y}}_{s}\right)-u\left(\overline{\hat{y}}_{s}\right)\right]-\bar{p}_{s} \bar{y}_{s}\right)+\left(u\left(\overline{\hat{y}}_{s}\right)-\bar{p}_{s} \overline{\hat{y}}_{s}\right) \\
\overline{W S}_{s} & =\left(\bar{w}_{s} \bar{l}_{s}-\left[v\left(\bar{l}_{s}+\overline{\hat{l}}_{s}\right)-v\left(\overline{\hat{l}}_{s}\right)\right]\right)+\left(\bar{w}_{s} \overline{\hat{l}}_{s}-v\left(\hat{\hat{l}}_{s}\right)\right) .
\end{aligned}
$$

That is, the surplus of consumers and workers can be decomposed into the surplus created by firm 1 (first bracketed terms in the above formulas) and the additional surplus attributable to firm 2 (second bracketed terms.

To be an "ideal" stakeholder firm, firm 1 would need to choose investment to maximize $\delta \sum_{s} \pi_{s}\left(\overline{C S}_{s}+\overline{W S}_{s}+\bar{R}_{s}+\overline{\hat{R}}_{s}\right)-\gamma\left(\pi_{s}\right)$ : this requires taking into account not only the difference between the good and the bad outcome for the profit of its shareholders and the surplus it generates for its consumers and workers, but also for the consumer and worker surpluses created by the other firms, as well as the profit of the other firms' shareholders. This is indeed an encompassing vision of who the stakeholders of the firm are, which is difficult to reconcile with competition between firms on the product and labor markets.

Realistically the most that can be expected of a corporation is that it take into account the interests of its own stakeholders - its shareholders, the consumers it serves and the workers it employs. Building on the notion of "value" of firm 1 for consumers and workers which we introduced in section 4.2, we can define the consumer and worker values

$$
\begin{aligned}
& C V_{s}\left(y_{s}, \hat{y}_{s}, p_{s}\right)=u\left(y_{s}+\hat{y}_{s}\right)-u\left(\hat{y}_{s}\right)-p_{s} y_{s} \\
& W V_{s}\left(l_{s}, \hat{l}_{s}, w_{s}\right)=w_{s} l_{s}-\left[v\left(l_{s}+\hat{l}_{s}\right)-v\left(\hat{l}_{s}\right)\right]
\end{aligned}
$$

$C V_{s}$ and $W V_{s}$ are the money equivalent of the increase in utility attributable to the ability to buy from firm 1 for the consumers, and to work for firm 1 for the workers, taking the decisions of other firms as given. The consumer and worker values are firm 1's contribution to the total consumer and worker surpluses - but are not equal to the total surpluses. 
It is difficult to describe a market structure on which these values are elicited using a model where the two firms produce a homogeneous good. The value $C V_{s}$ needs to be understood as the limit of the price of a c-right in a model with differentiated goods, when the goods become very close substitutes. If the goods produced by firm 1 and 2 were differentiated, the representative consumer would be willing to pay $u\left(y_{s}, \hat{y}_{s}\right)-u\left(0, \hat{y}_{s}\right)-p_{s} y_{s}$ for the right to buy from firm 1 , when the other firm produces $\hat{y}_{s}$ (per capita) and $p_{s}$ is the price of good sold by firm 1 . A model with differentiated goods is certainly natural for large firms, but outside the scope of this paper. We thus study the property of a stakeholder value equilibrium in which firm 1's manager is instructed to maximize the total value that the firm creates for its stakeholders, leaving the study of the implementation of the equilibrium for further research.

Note that we no longer need to assume that firm 1 maximizes its profit on the spot markets taking prices as given. To see this, assume as before that $\hat{f}$ represents a competitive fringe, that is $\hat{f}(\hat{l})=\max \left\{\sum_{j=1}^{n} \hat{f}^{j}\left(\hat{l}^{j}\right) \mid \sum_{j} \hat{l}^{j}=\hat{l}\right\}$ where $n$ is large, so that for the firms $j=1, \ldots, n$ the competitive assumption is (approximately) satisfied. On the other hand firm 1 chooses $\left(l_{s}, y_{s}\right)$ so as to maximize the total value for its stakeholders

$$
\left[u\left(y_{s}+\hat{y}_{s}\right)-u\left(\hat{y}_{s}\right)-p_{s} y_{s}\right]+\left[w_{s} l_{s}-\left[v\left(l_{s}+\hat{l}_{s}\right)-v\left(\hat{l}_{s}\right)\right]+\left[p_{s} y_{s}-w_{s} l_{s}\right]\right.
$$

under the constraints $y_{s}=f\left(l_{s}\right), p_{s}=u^{\prime}\left(y_{s}+\hat{y}_{s}\right), w_{s}=v^{\prime}\left(l_{s}+\hat{l}_{s}\right)$, taking $\left(\hat{l}_{s}, \hat{y}_{s}\right)$ as given. The terms involving prices in the objective function cancels (the revenue is a transfer from consumer to shareholders and the wages a transfer from shareholders to workers) and the first-order condition for the optimal choice of labor satisfies

$$
u^{\prime}\left(f\left(l_{s}\right)+\hat{y}_{s}\right) f^{\prime}\left(l_{s}\right)=v^{\prime}\left(l_{s}+\hat{l}_{s}\right)
$$

Since the other firm maximizes its profit taking prices as given, the first-order conditions (5) for a maximum of social welfare in outcome $s$ are satisfied, so that the property that the spot equilibrium prices are the competitive prices is no longer an assumption but follows from the maximization of the stakeholder value criterion. Alternatively we could assume that firm 2 is a large firm which maximizes a stakeholder criterion and it would also follow that the prices on the spot markets are the competitive prices.

Definition 3. A stakeholder equilibrium of the economy $\mathcal{E}$ is a pair of actions and prices $\left(\left(\bar{\ell}, \bar{c}, \pi^{s t v}, \bar{l}, \overline{\hat{l}}\right),(\bar{w}, \bar{p})\right)$ such that (i), (ii), (iv),(v) of Definition 1 hold, and (iii) is replaced by

(iii' $^{\prime}\left(\bar{l}, \pi^{s t v}, \bar{p}, \bar{w}\right)$ maximize the total value of firm 1 net of the investment cost

$$
T V(w, p)=\frac{1}{1+r} \sum_{s=g, b}\left(C V_{s}\left(y_{s}, p_{s}\right)+W V_{s}\left(l_{s}, w_{s}\right)+R\left(l_{s}, w_{s}, p_{s}\right)\right)-\gamma(\pi)
$$

under the constraints $y_{s}=f\left(l_{s}\right), p_{s}=u^{\prime}\left(y_{s}+\overline{\hat{y}}_{s}\right), w_{s}=v^{\prime}\left(l_{s}+\overline{\hat{l}}_{s}\right)$.

In this definition we have kept the interpretation of firm 2 as a competitive fringe. As we discussed above, the spot prices and the labor allocation is the same as in the shareholder 
equilibrium. However the change in the criterion for firm 1 changes the FOC for the choice of investment which becomes

$$
\left.\frac{1}{1+r}\left[\left(\overline{C V}_{g}-\overline{C V}_{b}\right)+\left(\overline{W V}_{g}-\overline{W V}_{b}\right)+\left(\bar{R}_{g}-\bar{R}_{b}\right)\right]=\gamma^{\prime s t v}\right)
$$

where the values are calculated at the spot market equilibrium. Adding the difference in consumer and worker values between the good and bad outcomes to the difference in profit, which is taken into account in the shareholder equilibrium, increases the perceived benefit by firm 1 to achieving a good outcome, thus leading to an increase in investment. To compare $\pi^{\text {stv }}$ with the optimal investment $\pi^{*}$, note that

$$
\overline{T V}_{s}=u\left(\bar{y}_{s}+\overline{\hat{y}}_{s}\right)-u\left(\overline{\hat{y}}_{s}\right)-\bar{p}_{s} \bar{y}_{s}+\bar{w}_{s} \bar{l}_{s}-\left(v\left(\bar{l}_{s}+\overline{\hat{l}}_{s}\right)-v\left(\overline{\hat{l}}_{s}\right)\right)+\bar{p}_{s} \bar{y}_{s}-\bar{w}_{s} \bar{l}_{s}
$$

so that

$$
\overline{T V}_{s}=\bar{W}_{s}-\widehat{W}_{s}, \quad \text { where } \widehat{W}_{s}=u\left(\overline{\hat{y}}_{s}\right)-v\left(\overline{\hat{l}}_{s}\right)
$$

$\widehat{W}_{s}$ is the social welfare that can be attributed to firm 2 in the thought experiment in which firm 1 is absent from the market, and the total value of firm 1 is the difference between the total social welfare and that attributable to firm 2. The FOC for optimal investment in a stakeholder value equilibrium is

$$
\left.\frac{1}{1+r}\left[\left(\bar{W}_{g}-\bar{W}_{b}\right)-\left(\widehat{W}_{g}-\widehat{W}_{b}\right)\right]=\gamma^{\prime s t v}\right)
$$

while $\pi^{*}$ is defined by $\frac{1}{1+r}\left(\bar{W}_{g}-\bar{W}_{b}\right)=\gamma^{\prime}\left(\pi^{*}\right)$. It is intuitive that firm 2 will "fill in" for firm 1 when firm 1 has a bad outcome: as a result firm 2 should produce more and create more surplus in outcome $b$ than in outcome $g$. Let us show that this is indeed the case, so that (33) implies that there is over-investment at a stakeholder value equilibrium

Proposition 5. In a stakeholder equilibrium of the benchmark model $(f, \hat{f})$ with $\hat{f} \neq 0$ there is over-investment: $\pi^{\text {stv }}>\pi^{*}$.

Proof: In view of (33) it remains to show that $\widehat{W}_{g}<\widehat{W}_{b}$. Firm 2's surplus function $\widehat{W}(\hat{l}) \equiv$ $u(\hat{f}(\hat{l}))-v(\hat{l})$ is concave, satisfies $\widehat{W}(0)=0$ and has a maximum for $\hat{l}^{m}$ defined by

$$
\widehat{W}^{\prime}\left(\hat{l}^{m}\right)=u^{\prime}\left(\hat{f}\left(\hat{l}^{m}\right)\right) \hat{f}^{\prime}\left(\hat{l}^{m}\right)-v^{\prime}\left(\hat{l}^{m}\right)=0
$$

For $\hat{l}<\hat{l}^{m}, \widehat{W}(\hat{l})$ is increasing. Thus if we show that (i) $\hat{l}_{g}<\hat{l}_{b}$ and (ii) $\hat{l}_{b} \leq \hat{l}^{m}$, then it follows that $\widehat{W}_{g}<\widehat{W}_{b}$. (i) can be deduced from Lemma 3, which is proved in the Appendix.

Lemma 3. $\hat{l}_{g}<\hat{l}_{b}$.

To show (ii) first suppose that $f_{b} \equiv 0$, i.e. in the bad outcome firm 1 and does not produce. Then firm 2 is the only producer on the market and, assuming price taking behavior, chooses $\overline{\hat{l}}_{b}$ so that $\bar{p}_{b} \hat{f}^{\prime}\left(\overline{\hat{l}}_{b}\right)=\bar{w}_{b}$. Since $\bar{p}_{b}=u^{\prime}\left(\hat{f}\left(\overline{\hat{l}}_{b}\right)\right)$ and $\bar{w}_{b}=v^{\prime}\left(\overline{\hat{l}}_{b}\right)$ it follows that $u^{\prime}\left(\hat{f}\left(\overline{\hat{l}}_{b}\right)\right) \hat{f}^{\prime}\left(\overline{\hat{l}}_{b}\right)-$ $v^{\prime}\left(\overline{\hat{l}}_{b}\right)=0$, so that $\overline{\hat{l}}_{b}=\hat{l}^{m}$. Since, by Lemma $3, \hat{l}_{g}<\hat{l}_{b}$, it follows that $\widehat{W}_{g}<\widehat{W}_{b}$. To extend the 
result to the case where $f_{b}>0$, consider a related economy $\widetilde{\mathcal{E}}$ for which $\tilde{f}_{g}=f_{b}$ and $\tilde{f}_{b} \equiv 0$. Applying the above reasoning to $\widetilde{\mathcal{E}}$, we find $\tilde{\hat{l}}_{b}=\hat{l}^{m}$ and $\tilde{\hat{l}}_{g}=\overline{\hat{l}}_{b}<\hat{l}^{m}$.

The stakeholder value criterion asks firm 1 to bear in mind the increased surplus that will accrue to its workers and consumers if it succeeds in obtaining the good outcome. However the optic that the criterion induces fails to take into account the response of firm 2 . When firm 1 has a good outcome, firm 2 faces stiffer competition and a lower output price and produces less than in outcome $b$, thereby creating a smaller surplus. Since the surpluses of the two firms move in opposite directions, an investment decision based solely on the surplus created by firm 1 exaggerates the gain in outcome $g$ and leads to over-investment. Thus Proposition 1 asserts that pure profit underestimates the benefit of investment, while Proposition 5 asserts that surplus value overestimates it. In the next proposition we show that a firm that gives a (small) positive weight to its consumers and workers (on top of its shareholders) improves on the shareholder equilibrium.

We say that firm 1 is stakeholder oriented if it maximizes a criterion of the form

$$
V(\pi ; \theta)=\frac{1}{1+r} \sum_{s=g, b} \pi_{s}\left[R_{s}\left(\bar{w}_{s}, \bar{p}_{s}\right)+\theta\left(C V_{s}\left(\bar{p}_{s}\right)+W V_{s}\left(\bar{w}_{s}\right)\right)\right]-\gamma(\pi)
$$

for some positive $\theta$, taking spot prices $\left(\bar{w}_{s}, \bar{p}_{s}\right)_{s=g, b}$ as given. ${ }^{26}$ An equilibrium with a stakeholder oriented firm 1 is the same as a shareholder equilibrium with the sole difference that the criterion Definition 1 (iii) is replaced by the criterion $V(\pi ; \theta)$. The improvement obtained by replacing the profit criterion by $V(\pi ; \theta)$ can be formalized as follows.

Proposition 6. (Stakeholder-Oriented Firm) If firm 1 uses the criterion $V(\pi ; \theta)$ with a small $\theta$, then the stakeholder-oriented equilibrium improves on the shareholder equilibrium.

Proof: For any $\theta \geq 0$, the equilibrium with criterion $V(\pi ; \theta)$ leads to the same spot prices $(\bar{w}, \bar{p})$ and the same labor choices $(\bar{l}, \overline{\hat{l}})$ as in the shareholder equilibrium. The choice of investment $\pi(\theta)$ which maximizes $V(\pi ; \theta)$ is defined by the first-order condition

$$
V_{\pi}(\pi, \theta)=\frac{1}{1+r}\left[\bar{R}_{g}+\theta\left(\overline{C V}_{g}+\overline{W V}_{g}\right)\right]-\left[\bar{R}_{b}+\theta\left(\overline{C V}_{b}+\overline{W V}_{b}\right)\right]-\gamma^{\prime}(\pi)=0
$$

which, when $\overline{C V}_{s}$ and $\overline{W V}_{s}$ are replaced by their expressions in (32), can be written as

$$
\frac{1}{1+r}\left[(1-\theta)\left(\bar{R}_{g}-\bar{R}_{b}\right)+\theta\left(\left(\bar{W}_{g}-\bar{W}_{b}\right)-\left(\widehat{W}_{g}-\widehat{W}_{b}\right)\right)\right]-\gamma^{\prime}(\pi(\theta))=0 .
$$

Differentiating (34) gives

$$
\frac{1}{1+r}\left[-\left(\bar{R}_{g}-\bar{R}_{b}\right)+\left(\left(\bar{W}_{g}-\bar{W}_{b}\right)-\left(\widehat{W}_{g}-\widehat{W}_{b}\right)\right)\right]=\gamma^{\prime \prime}(\pi(\theta)) \pi^{\prime}(\theta)
$$

\footnotetext{
${ }^{26}$ If the stakeholder-oriented firm were permitted to use its market power on the spot markets, the prices would be different from the competitive prices $(\bar{w}, \bar{p})$ because of the substantial weight of the shareholders in the criterion. The relevant comparison would then be between the shareholder equilibrium in which the firm exercises its market power and the equilibrium with the stakeholder-oriented firm also exercizing market power. Such a comparison is outside the scope of this paper.
} 
Proposition 1 implies $\left(\bar{W}_{g}-\bar{W}_{b}\right)-\left(\bar{R}_{g}-\bar{R}_{b}\right)>0$, and Proposition 4 implies $\left(\widehat{W}_{g}-\widehat{W}_{b}\right)<0$. Since $\gamma^{\prime \prime}>0, \pi^{\prime}(\theta)>0$.

Let $W(\theta)=\delta \sum_{s=g, b} \pi_{s}(\theta) \bar{W}_{s}-\gamma(\pi(\theta))$ denote the discounted expected social welfare induced by the investment $\pi(\theta)$, with derivative $W^{\prime}(\theta)=\pi^{\prime}(\theta)\left(\delta\left(\bar{W}_{g}-\bar{W}_{b}\right)-\gamma^{\prime}(\pi(\theta))\right)$. Since $\gamma^{\prime \prime}>0$ and $\pi^{\prime}>0, \gamma^{\prime}(\pi(\theta))$ is increasing. Since by Proposition $1, \delta\left(\bar{W}_{g}-\bar{W}_{b}\right)>\gamma^{\prime}(\pi(0)), W^{\prime}(0)$ is positive. Thus social welfare increases for $\theta$ small enough, which proves the proposition.

\section{Conclusion}

Berle and Means (1932) classic study of the corporation is best known for showing that the emergence of the very large scale modern corporation led inevitably to the separation between ownership and control, and that as a result incentives have to be created to induce managers (the control) to perform their fiduciary duty to the shareholders. However in the final chapter on "The New Concept of the Corporation" they focused on another idea which has not been given the same attention - that at the end of the day, it is not at all clear that a corporation should be run exclusively in the interest of its shareholders. When a large corporation in the pursuit of its regular activities uses "private property" (financed by its shareholders), which in view of the scale of the corporation has important consequences for agents other than its shareholders, then the "privateness" of the property (and hence its fiduciary aspect) comes into question. As a result a large corporation must focus on the consequences of its actions for the interests of all parties with whom it interacts on a regular basis. ${ }^{27}$

This broader view of the responsibility of the corporation has not caught on in the UK or the US where it has even been vigorously attacked. To quote Friedman (1970) "there is one and only one social responsibility of business - to use its resources and engage in activities designed to increase its profits". In other countries, however, especially Germany, France and Japan, corporations are run in a way that is closer to a stakeholder approach with a significant weight placed on the workers. ${ }^{28}$ The results of a survey of managers reported by Yoshimori (1995) show that $97 \%$ of CEOs in Japan and $84 \%$ in Germany believed that a corporation should be run "for the interests of all stakeholders" whereas for the US $76 \%$ (for the UK 70\%) believed that "shareholder interest should be given first priority". Thus a stakeholder approach has made its way into the practice of some countries even though a widely accepted theory justifying this approach has yet to be worked out. ${ }^{29}$

\footnotetext{
${ }^{27}$... "neither the claims of ownership nor those of control can stand against the paramount interests of the community.... When a convincing system of community obligations is worked out and is generally accepted, in that moment the passive property right of today must yield before the larger interests of society. Should the corporate leaders, for example, set forth a system comprising fair wages, security to employees, reasonable service to their public, and stabilization of business, all of which would divert a portion of the profits from the owners of passive property, and should the community generally accept such a scheme as a logical and human solution of industrial difficulties, the interests of passive property owners would have to give way." (Berle-Means (1932, p. 310)).

${ }^{28}$ In Germany by law, the system of codetermination requires that representatives of the employees be involved in the strategic decisions of corporations; however consumers are not represented on the corporate boards.

${ }^{29}$ There is however a discussion of stakeholder theory in the management literature which defines a stakeholder firm as one which "pursues multiple objectives of parties with different interests" (Kochan-Rubinstein (2001)).
} 
A valid theoretical foundation for a stakeholder theory of the firm requires two preconditions: (1) decisions taken by the firms must have an external effect on stakeholders (2) these externalities must not be readily resolved by government intervention (regulation or taxation). To obtain an operational stakeholder theory, three additional conditions must be satisfied: it must be possible to

(i) assign well-defined benefits for each group of stakeholders

(ii) exhibit a way of assigning relative weights to the benefits of the different groups in (i) to obtain a well-defined objective for a firm

(iii) provide incentives to the firm's manager to maximize this objective.

Jensen $(2001)^{30}$ doubts that a stakeholder approach can provide a solution to (i) and (ii). Tirole (2001) argues that measuring consumer and worker surpluses may be difficult since there are no liquid markets on which they can be evaluated, akin to the stock market for the firms' profits. If (i) can not be solved then there is no solution to (ii), so that there is no well-defined criterion for evaluating a manager's performance. Like Jensen, Tirole argues that any attempt to take into account the interests of the different stakeholders leaves the firm open to manipulation by the management: "Management can almost always rationalize any action by invoking its impact on the welfare of some stakeholder" (Tirole (2001)).

Our analysis offers a first step to the solution of (i) and (ii): under the assumption of quasilinearity of agents' preferences, profit measures the benefits of shareholders, while consumer and worker surpluses measure the benefits accruing to consumers and workers. In the idealized case of an economy with a single firm the stakeholder objective, which leads to the social optimum, is to maximize the expected sum of these three benefits, i.e. it puts equal weight on each of the benefits in (i). However this theoretical result, while formally answering (i) and (ii), does not respond to Tirole's concern that consumer and worker surpluses may be difficult to evaluate in practice. We propose a solution to this difficulty by drawing on the Coasian idea of creating property rights for externalities: if the firm can issue consumer and worker rights, and if these rights can be traded on reasonably liquid markets, then their market prices will reveal the benefits that consumers and workers derive from being stakeholders of the firm. In effect our proposal would lead to reforming corporate accounting, by introducing new assets - employee and consumer surpluses - and corresponding liabilities - employee rights and consumer rights - in a spirit close to the proposal of Cornell-Shapiro (1987). ${ }^{31}$

If the elements of a stakeholder theory seem to fall into place in the idealized case of an economy with a single firm, extending the theory to the more general setting where several

\footnotetext{
30 "Stakeholder theory plays into the hands of managers by allowing them to pursue their own interests at the expense of the firm's financial claimants and society at large. It allows managers and directors to devote the firm's resources to their own favorite causes - the environment, art, cities, medical research.... By expanding the power of managers in this unproductive way, stakeholder theory increases the agency costs in the economic system" (Jensen (2001)).

${ }^{31}$ There is a theoretical literature that uses incomplete contracts models to explain why we see other forms of corporation than for profit: non-profit (Glaeser and Shleifer 2001), government ownership (Hart et al. 1997), cooperative (Hart and Moore 1998, Rey and Tirole 2000). There is also an early literature on labor managed firms. However this paper and the contemporaneous paper of Allen et al. (2011) are the only formal models of stakeholder firms (viewed as hybrids between for profit, consumers cooperatives and labor managed firms) that we are aware of.
} 
firms compete on the product and labor markets presents new difficulties. For in this setting, to achieve the social optimum each firm would need to take into account the effect of its investment on the expected utilities of all agents in the economy, including the consumers, workers and shareholders of the other firms. Placing the welfare of the stakeholders of competing firms directly into the objective function of a firm is not however a realistic proposal since it would come into conflict with competition on the spot markets, which is required for efficiency. Our analysis shows however that an investment that improves on the shareholder outcome is obtained if the firm's objective includes a positive, perhaps small, weight on just the surpluses of its own consumers and workers. Thus a straightforward modification of the pure profit criterion can lead to an improvement on capitalism. If full weight were placed on the surpluses of its own consumers and workers, then the firm would exaggerate the benefit of achieving a good outcome since it would neglect the fact that its competitors produce more and create more surplus for the economy when it is less productive. Modifying the stakeholder criterion by decreasing the weight placed on the surpluses of the firm's consumers and workers implicitly takes into account the offsetting surpluses created by the other firms.

There remain the informational and incentive problems of evaluating the surpluses and ensuring that they are in some measure taken into account by a firm's manager. These are problems which are not easily addressed with the simple model of this paper in which firms produce homogeneous goods using homogeneous labor. Extending the Coasian idea of creating consumer and worker rights requires that firms produce differentiated products and use different types of labor or in different locations. Since in a setting with heterogeneous firms, consumers, and workers, the price of a right will not reveal the full surplus, only the surplus of the marginal buyer, maximizing the total value of rights seems commensurate with the theoretical result that only a part a firm's consumer and worker surpluses should be taken into account. More research is needed to find robust and practical ways of introducing markets for consumer and worker rights, thereby enabling corporations to simultaneously take the interests of their stakeholders into account, while retaining an objective market-based criterion for measuring management performance.

\section{APPENDIX : Proofs}

Lemma 1: $W_{g}^{*}-W_{b}^{*}>\bar{R}_{g}-\bar{R}_{b}$.

Proof: Consider the parameterized family of production functions for firm 1

$$
f(t, l)=t f_{g}(l)+(1-t) f_{b}(l), \quad t \in[0,1]
$$

where the parameter takes the production function continuously from the bad to the good technology. We associate with each $t \in[0,1]$ a fictitious ' $t$ ' spot economy at date 1 with the characteristics $(u, v, f(t,),. \hat{f})$. The maximized social welfare for the $t$ economy is

$$
W(t)=\max \{u(c)-v(\ell) \mid c=f(t, l)+\hat{f}(\hat{l}), \ell=l+\hat{l}\}
$$

The solution $(c(t), \ell(t), l(t), \hat{l}(t))$ of this maximum problem is characterized by the equations

$$
\begin{aligned}
u^{\prime}(c(t)) f_{2}(t, l(t))=v^{\prime}(\ell(t)), & u^{\prime}(c(t)) \hat{f}^{\prime}(\hat{l}(t))=v^{\prime}(\ell(t)), \\
c(t)=f(t, l(t))+\hat{f}(\hat{l}(t), & \ell(t)=
\end{aligned}
$$


and this allocation can be induced by letting agents and firms make their choices on spot markets at prices

$$
p(t)=u^{\prime}(c(t)), \quad w(t)=v^{\prime}(l(t)) .
$$

Let $R(t)=p(t) f(t, l(t))-w(t) l(t)$ denote the (optimized) profit of firm 1 under these spot prices. We show that the function

$$
D(t)=W(t)-R(t)
$$

is strictly increasing on $[0,1]$ : this will imply that $D(1)=W_{g}^{*}-\bar{R}_{g}>D(0)=W_{b}^{*}-\bar{R}_{b}$ and hence establish the result. By the envelope theorem

$$
W^{\prime}(t)=u^{\prime}(c(t)) f_{1}(t, l(t)), \quad R^{\prime}(t)=p^{\prime}(t) f(t, l(t))+p(t) f_{1}(t, l(t))-w^{\prime}(t) l(t) .
$$

Thus $D^{\prime}(t)=-p^{\prime}(t) f(t, l(t))+w^{\prime}(t) l(t)$. Since (35) implies that the marginal products of labor are equalized, $f_{2}(t, l(t))=\hat{f}^{\prime}(\hat{l}(t))$, it follows that

$$
p^{\prime}(t)=u^{\prime \prime}(c(t))\left[f_{1}(t, l(t))+f_{2}(t, l(t))\left(l^{\prime}(t)+\hat{l}^{\prime}(t)\right)\right], \quad w^{\prime}(t)=v^{\prime \prime}(\ell(t))\left(l^{\prime}(t)+\hat{l}^{\prime}(t)\right) .
$$

The change in the optimal allocation of labor to the two firms $\left(l^{\prime}(t), \hat{l}^{\prime}(t)\right)$ can be obtained by differentiating the FOCs for the optimal allocation of labor (35). This gives the pair of linear equations

$$
\begin{aligned}
& u^{\prime \prime}\left(f_{1}+f_{2}\left(l^{\prime}+\hat{l}^{\prime}\right)\right) f_{2}+u^{\prime}\left(f_{21}+f_{22} l^{\prime}\right)-v^{\prime \prime}\left(l^{\prime}+\hat{l}^{\prime}\right)=0 \\
& u^{\prime \prime}\left(f_{1}+f_{2}\left(l^{\prime}+\hat{l}^{\prime}\right)\right) f_{2}+u^{\prime} \hat{f}^{\prime \prime} \hat{l}^{\prime}-v^{\prime \prime}\left(l^{\prime}+\hat{l}^{\prime}\right)=0,
\end{aligned}
$$

where the arguments of the functions have been omitted to simplify notation. Solving these equations leads to

$$
l^{\prime}+\hat{l}^{\prime}=\frac{-u^{\prime \prime} f_{1} f_{2}\left(f_{22}+\hat{f}^{\prime \prime}\right)-u^{\prime} f_{21} \hat{f}^{\prime \prime}}{u^{\prime} \hat{f}^{\prime \prime} f_{22}+\left(u^{\prime \prime}\left(f_{2}\right)^{2}-v^{\prime \prime}\right)\left(f_{22}+\hat{f}^{\prime \prime}\right)} .
$$

The denominator is positive since $f_{22}, \hat{f}^{\prime \prime}, u^{\prime \prime}$ are negative and $v^{\prime \prime}$ is positive, while the sign of the numerator is ambiguous. However substituting this expression into $D^{\prime}(t)=-u^{\prime \prime} f_{1} f+$ $\left(v^{\prime \prime} l-u^{\prime \prime} f_{2} f\right)\left(l^{\prime}+\hat{l}^{\prime}\right)$ gives

$$
D^{\prime}(t)=\frac{1}{d e n}\left[u^{\prime \prime} u^{\prime} f \hat{f}^{\prime \prime}\left(f_{21} f_{2}-f_{1} f_{22}\right)+u^{\prime \prime} v^{\prime \prime} f_{1}\left(f_{22}+\hat{f}^{\prime \prime}\right)\left(f-f_{2} l\right)-u^{\prime} v^{\prime \prime} \hat{f}^{\prime \prime} f_{21} l\right]
$$

where "den" is the positive denominator of $l^{\prime}+\hat{l}^{\prime}$. Since by concavity of $f, f-f_{2} l>0$, all the terms are positive and $D^{\prime}(t)>0$ : thus moving toward the good outcome constantly increases the welfare by more than the increase in profit.

Proof of Lemma 2. Consider the $(t, \tau)$ economy in which the production functions of the two firms are $f(t, l)=t f_{g}(l)+(1-t) f_{b}(l), \quad \hat{f}(\tau, \hat{l})=\tau \hat{f}_{g}(\hat{l})+(1-\tau) \hat{f}_{b}(\hat{l})$, and the consumers and workers have the characteristics $(u, v)$. The maximum social welfare in the $(t, \tau)$ economy is

$$
W(t, \tau)=\max \{u(c)-v(\ell) \mid c=f(t, l)+\hat{f}(\tau, \hat{l}), \ell=l+\hat{l}\}
$$


We show that $\frac{\partial^{2} W}{\partial t \partial \tau}<0$, which proves the lemma since it implies $W(1,1)-W(0,1)<W(1,0)-$ $W(0,0) \Longleftrightarrow W_{g g}^{*}-W_{b g}^{*}<W_{g b}^{*}-W_{b b}^{*}$.

$$
\frac{\partial W}{\partial \tau}=u^{\prime}(c(t, \tau)) \hat{f}_{1}(\tau, \hat{l}(t, \tau)), \quad \frac{\partial^{2} W}{\partial t \partial \tau}=u^{\prime \prime}\left(f_{1}+f_{2}\left(\frac{\partial l}{\partial t}+\frac{\partial \hat{l}}{\partial t}\right)\right) \hat{f}_{1}+u^{\prime} \hat{f}_{12} \frac{\partial \hat{l}}{\partial t}
$$

where the arguments of the function in the second derivative have been omitted to simplify the expression. As in the proof of Proposition $1, \frac{\partial l}{\partial t}$ and $\frac{\partial \hat{l}}{\partial t}$ can be calculated by differentiating the FOCs of the maximum problem (39). Calculations similar to those in the proof of Proposition 1 lead to

$$
u^{\prime \prime} \hat{f}_{1}\left(f_{1}+f_{2}\left(\frac{\partial l}{\partial t}+\frac{\partial \hat{l}}{\partial t}\right)\right)=u^{\prime \prime} \hat{f}_{1} \frac{u^{\prime} f_{1} f_{22} \hat{f}_{22}-v^{\prime \prime} f_{1}\left(f_{22}+\hat{f}_{22}\right)-u^{\prime} f_{2} f_{21} \hat{f}_{22}}{u^{\prime} f_{22} \hat{f}_{22}+\left(u^{\prime \prime}\left(f_{2}\right)^{2}-v^{\prime \prime}\right)\left(f_{22}+\hat{f}_{22}\right)}
$$

which is negative since the numerator and the denominator of the fraction on the right side are positive. From the calculation in the proof of Proposition 1 we also deduce

$$
\frac{\partial \hat{l}}{\partial t}=\frac{1}{u^{\prime} \hat{f}_{22}}\left(\left(v^{\prime \prime}-u^{\prime \prime}\left(f_{2}\right)^{2}\right)\left(\frac{\partial l}{\partial t}+\frac{\partial \hat{l}}{\partial t}\right)-u^{\prime \prime} f_{1} f_{2}\right)
$$

which after substituting the value of $\frac{\partial l}{\partial t}+\frac{\partial \hat{l}}{\partial t}$ gives

$$
\frac{\partial \hat{l}}{\partial t}=\frac{-u^{\prime} f_{21} \hat{f}_{22}\left(v^{\prime \prime}-u^{\prime \prime}\left(f_{2}\right)^{2}\right)-u^{\prime} u^{\prime \prime} f_{1} f_{2} f_{22} \hat{f}_{22}}{u^{\prime} \hat{f}_{22} \operatorname{den}}
$$

where "den" is the positive denominator in (40). The numerator of the fraction is positive, den is positive and since $\hat{f}_{22}<0, \frac{\partial \hat{l}}{\partial t}<0$. This property is intuitive: if the productivity of firm 1 increases the amount of labor used by firm 2 in the efficient allocation decreases. Thus the two terms in $\frac{\partial^{2} W}{\partial t \partial \tau}$ are negative and the result follows.

Proof of Lemma 3. To prove $\hat{l}_{b}>\hat{l}_{g}$ it is sufficient to prove that $\hat{l}^{\prime}(t)<0$, where $\hat{l}(t)$ is the optimal choice of labor by firm 2 in the artificial $t$ economy introduced in the proof of Proposition 1. It follows from (37) that

$$
\hat{l}^{\prime}=\frac{\left(v^{\prime \prime}-u^{\prime \prime}\left(f_{2}\right)^{2}\right)\left(l^{\prime}+\hat{l}^{\prime}\right)-u^{\prime \prime} f_{1} f_{2}}{u^{\prime} \hat{f}^{\prime \prime}}
$$

Inserting the value of $l^{\prime}+\hat{l}^{\prime}$ into (38) leads to

$$
\hat{l}^{\prime}=\frac{-u^{\prime} f_{21} \hat{f}^{\prime \prime}\left(v^{\prime \prime}-u^{\prime \prime}\left(f_{2}\right)^{2}\right)-u^{\prime} u^{\prime \prime} f_{1} f_{2} \hat{f}^{\prime \prime} f_{22}}{u^{\prime} \hat{f}^{\prime \prime} d e n}<0,
$$

where den denotes the positive denominator of (39). Thus $\hat{l}(1)=\hat{l}_{g}<\hat{l}(0)=\hat{l}_{b}$, which proves the Lemma. 


\section{References}

Acemoglu, D. (2009) Introduction to Modern Economic Growth, Princeton: Princeton University Press.

Acemoglu, D. and A. Simsek (2010), "Moral Hazard and Efficiency in General Equilibrium with Anonymous Trading", http://economics.mit.edu/files/5523.

Aghion, P. and P.W. Howitt (1998), Endogenous Growth Theory. Cambridge, Mass: MIT Press.

Allen, F., E. Carletti and R. Marquez (2011), "Stakeholder Capitalism, Corporate Governance and Firm Value", Discussion Paper http://ssrn.com/abstract=9681411.

Arrow, K.J. (1971), "Appendix to: The Role of Securities in the Optimal Allocation of Risk Bearing", in Theory of Risk Bearing, Chicago: Markham Publishing Company.

Berle, A.A. and G.C. Means (1932), The Modern Corporation and Private Property, New-York: Harcourt, Brace and World.

Blanchard, O.J. and J. Tirole (2004), "The Joint Design of Unemployment Insurance and Employment Protection: A First Pass", http://ssrn.com/abstract=527882.

Bisin, A. and P. Gottardi (1999), "Competitive Equilibria with Asymmetric Information," Journal of Economic Theory, 87, 1-48.

Cornell, B. and A.C. Shapiro (1987), "Corporate Stakeholder and Corporate Finance," Financial Management, 16, 5-14.

Coase, R.H. (1960), "The Problem of Social Cost," Journal of Law and Economics, 3, 1-44.

Demichelis, S. and K. Ritzberger (2011), "A General Equilibrium Analysis of Corporate Control and the Stock Market," Economic Theory, 46, 221-254.

Friedman, M. (1970), "Social Responsibility of Business", The New York Times, September 13, 1970; reprinted in An Economist's Protest, New-Jersey: Thomas Horton and Co. (1972).

Glaeser, E. and A. Shleifer (2001), "Not-for-profit Entrepreneurs", J. of Public Econ., 81, 99-115.

Greenwald, B.C. and J.E. Stiglitz (1986), "Externalities in Economies with Imperfect

Information and Incomplete Markets", The Quarterly Journal of Economics, 101(2), 229-264.

Hart, O.D. and J. Moore (1998), "Cooperatives vs. Outside Ownership," NBER Working Paper No. w6421. Available at SSRN: http://ssrn.com/abstract=226168.

Hart, O.D., Shleifer, A. and R.W. Vishny (1997), "The Proper Scope of Government: Theory and an Application to Prisons", Quarterly Journal of Economics, Vol. 112, 1127-1161.

Hellwig, M. and A. Irmen (2001), "Endogenous Technical Change in a Competitive Economy," Journal of Economic Theory, 101, 1-39.

Jensen, M. (2001), "Value Maximization, Stakeholder Theory and the Corporate Objective Function", Journal of Applied Corporate Finance, 14, 8-21.

Kochan, T.A. and S.A. Rubinstein (2000), "Toward a Stakeholder Theory of the Firm: the Saturn Partnership", Organization Science, 11, 367-386. 
Laffont, J.J. (1989), Fundamentals of Public Economics, Cambridge: M.I.T. Press.

Lisboa, Marcos (2001), "Moral Hazard and General Equilibrium in Large Economies," Economic Theory, 18, 555-585.

Magill, M. and M. Quinzii (2009), "The Probability Approach to General Equilibrium with Production", Economic Theory, 39, 1-41.

Mankiw, G. and M.D. Whinston (1986), "Free Entry and Social Inefficiency", the Rand Journal of Economics, 17, 48-58.

Mas-Colell, A. (1985), The Theory of General Economic Equilibrium: A Differentiable Approach, Cambridge: Cambridge University Press.

Michelacci, C. and V. Quadrini (2005), "Borrowing from Employees: Wage Dynamics with Financial Constraints," Journal of the European Economic Association, 3-2.3, 360-369.

Michelacci, C. and V. Quadrini (2009), "Financial Markets and Wages," Review of Economic Studies, 76, 795-827.

Morgan J. and J. Tumlinson (2012), "Corporate Provision of Public Goods," Discussion Paper, http://ssrn.com/abstract=2077969.

Prescott, E.C. and R.M. Townsend (1984a), "Pareto Optima and Competitive Equilibria with Adverse Selection and Moral Hazard", Econometrica, 52, 21-46.

Prescott, E.C. and R.M. Townsend (1984b), "General Competitive Analysis in an Economy with Private Information", International Economic Review, 25, 1-20.

Rey, P. and J. Tirole (2000), "Loyalty and Investment in Cooperatives," IDEI, Toulouse. Shleifer, A and R.W. Vishny (1997), "A Survey of Corporate Governance," Journal of Finance, 52, 737-783.

Tirole, J. (1988), The Theory of Industrial Organization, Cambridge, Mass: MIT Press.

Tirole, J. (2001), "Corporate Governance", Econometrica, 69, 1-35.

Tirole, J. (2006), The Theory of Corporate Finance, Princeton: Princeton University Press.

Yoshimori, M. (1995), "Whose Company Is It: The Concept of Corporation in Japan and in the West," Long Range Planning, 28, 33-44.

Zame W. R. (2007), "Incentives, Contracts and Markets: A General Equilibrium Theory of Firms," Econometrica, 75, 1453-1500. 